\title{
Tropical Indian Ocean warming contributions to China winter climate trends since 1960
}

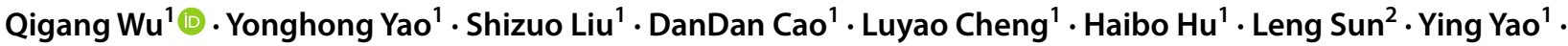 \\ Zhiqi Yang ${ }^{1} \cdot$ Xuxu Gao ${ }^{3} \cdot$ Steven R. Schroeder ${ }^{4}$
}

Received: 5 June 2017 / Accepted: 18 December 2017 / Published online: 11 January 2018

(c) The Author(s) 2018. This article is an open access publication

\begin{abstract}
This study investigates observed and modeled contributions of global sea surface temperature (SST) to China winter climate trends in 1960-2014, including increased precipitation, warming through about 1997, and cooling since then. Observations and Atmospheric Model Intercomparison Project (AMIP) simulations with prescribed historical SST and sea ice show that tropical Indian Ocean (TIO) warming and increasing rainfall causes diabatic heating that generates a tropospheric wave train with anticyclonic 500-hPa height anomaly centers in the TIO or equatorial western Pacific (TIWP) and northeastern Eurasia (EA) and a cyclonic anomaly over China, referred to as the TIWP-EA wave train. The cyclonic anomaly causes Indochina moisture convergence and southwesterly moist flow that enhances South China precipitation, while the northern anticyclone enhances cold surges, sometimes causing severe ice storms. AMIP simulations show a 1960-1997 China cooling trend by simulating increasing instead of decreasing Arctic 500-hPa heights that move the northern anticyclone into Siberia, but enlarge the cyclonic anomaly so it still simulates realistic China precipitation trend patterns. A separate idealized TIO SST warming simulation simulates the TIWP-EA feature more realistically with correct precipitation patterns and supports the TIWP-EA teleconnection as the primary mechanism for long-term increasing precipitation in South China since 1960. Coupled Model Intercomparison Project (CMIP) experiments simulate a reduced TIO SST warming trend and weak precipitation trends, so the TIWP-EA feature is absent and strong drying is simulated in South China for 1960-1997. These simulations highlight the need for accurately modeled SST to correctly attribute regional climate trends.
\end{abstract}

Keywords Tropical Indian Ocean · Sea surface temperature - AMIP · Climate trends · East Asian Winter Monsoon · Precipitation · China

\section{Introduction}

Previous traditional Atmospheric Model Intercomparison Project (AMIP) experiments, forced by prescribed historical sea surface temperature (SST) and sea ice, successfully capture many aspects of observed climate variations

Qigang Wu

qigangwu@nju.edu.cn

1 School of Atmospheric Sciences, Nanjing University, Nanjing 210023, Jiangsu, China

2 National Climate Center, China Meteorological Administration, Beijing 100081, China

3 Hebei Climate Center, Shijiazhuang 050021, Hebei, China

4 Department of Atmospheric Sciences, Texas A\&M University, College Station, TX, USA around the globe (e.g., Gates et al. 1999; Schneider et al. 2003; Deser et al. 2004; Hurrell et al. 2004; Schubert et al. 2004). Some studies further examine the relative effects of observed and direct atmospheric radiative forcing (due to observed changes in well-mixed greenhouse gases, ozone, sulfate aerosols, volcanic eruptions and solar irradiance) on global winter surface air temperature (SAT), precipitation and atmospheric circulation trends with atmospheric general circulation models (AGCMs) (Compo and Sardeshmukh 2009; Deser and Phillips 2009; Dommenget 2009; Pegion and Kumar 2010; Chan and Wu 2015). These studies conclude that most land warming is caused indirectly by ocean warming and not by the direct local response to radiative forcings, thus emphasizing the significant role of remote oceanic influences on continental warming. If SST changes are prescribed only in the tropics, with climatological SST elsewhere, models still produce reasonable trends even in 
the extratropics, indicating that tropical oceans are the main driver of extratropical SAT and precipitation responses to climate forcing (e.g., Hoerling et al. 2004; Hurrell et al. 2004; Lu et al. 2004; Deser and Phillips 2009). Shin and Sardesmukh (2011) found that the recent trend patterns of SAT and precipitation over North America, Europe and North Africa have been strongly influenced by the warming pattern of the tropical oceans. Gradual tropical Indian Ocean (TIO) SST warming has been the main contributor to the positive polarity of the North Atlantic Oscillation (NAO) and associated North Atlantic and European winter climate changes during 1950-1999 (Hurrell et al. 2004; Hoerling et al. 2004). The physical link by which tropical forcing affects extratropical atmospheric circulation involves diabatic heating anomalies caused by tropical rainfall changes (Hoskins and Karoly 1981). The generation of extratropical circulation anomalies corresponding to the Pacific-North America (PNA) teleconnection pattern by tropical forcing can be explained by existing linear theory and known atmospheric wave dynamics (e.g., Trenberth et al. 1998). A NAOlike response to an Indian Ocean SST anomaly most likely involves synoptic eddy feedbacks that cause changes in the North Atlantic storm track (Hoerling et al. 2004).

Many interannual and decadal climate variations in China have been attributed to tropical Pacific and Indian Ocean SST variations. El Niño often peaks in winter and is usually associated with a weak East Asian winter monsoon (EAWM) with mild and wet conditions in China (Zhang et al. 1996; Wang et al. 2000), and cold winters south of $40^{\circ} \mathrm{N}$ in East Asia are often preceded by development of La Niña episodes (Wang et al. 2010). At the interannual time scale, some studies connect ENSO with two Indian Ocean SST modes, namely the Indian Ocean basin (IOB) mode and Indian Ocean Dipole (IOD) mode, which in turn affect the East Asia climate. The warm (cold) IOB phase is found to occur in the spring following an El Niño (La Niña) event. Yang et al. (2007) proposed that the IOB mode acts to accumulate and prolong the ENSO influence until the following summer, and intensifies the East Asian summer monsoon (EASM) by inducing an anticyclonic anomaly in the lower troposphere over the subtropical northwestern Pacific. The peak IOD SST anomaly appears in the fall and shows a strong link to the Asian winter monsoon (Yang et al. 2010). Zheng et al. (2013) reported that convective heating associated with the leading interannual rainfall variability mode in the tropical Indo-Western Pacific (IWP), which is highly related to IOD in autumn and to ENSO in winter, can generate a wave train from the IWP to East Asia and the northwestern Pacific that has significant impacts on Asian climate. On the decadal time scale, Pacific Basin SST variations substantially influence the EAWM and China climate (Li and Xian 2003; Wang et al. 2008), and SST anomalies over the TIO also have significant impacts on winter SAT variations over East Asia (Wang et al. 2010). Some studies reveal that the North Pacific Gyre Oscillation (NPGO), defined as the second pattern of North Pacific SST variability (Di Lorenzo et al. 2008), has significant impacts on the East Asian climate on the interannual scale (e.g., Wang et al. 2007; Choi et al. 2011), and also on the decadal time scale (Ye et al. 2017).

On longer time scales, the EAWM weakened starting in the mid-1960s, coinciding with a weakening Siberia High and stronger warming in northern China (Liang et al. 2014; Wang and Chen 2014; Ding et al. 2014; also, Figs. 1, 2). However, since the late 1990s there has been a fast Siberia High recovery with a stronger EAWM and winter cooling in China (Jeong et al. 2011; Wang and Chen 2014), which may be associated with an increase in Eurasian snow cover or Arctic sea ice loss in the last two decades (Jeong et al. 2011; Wu et al. 2011, 2015). In South China, where the average winter temperature is above $5^{\circ} \mathrm{C}$ (Fig. 1d), China precipitation is heaviest (>200 $\mathrm{mm}$ in winter, Fig. 1f) and has significantly increased since the 1960s, and several prolonged ice storm events have caused severe damage in recent decades (Zhai et al. 2005; Sun and Ao 2013; Li et al. 2015; also Fig. 3). Through comparisons of observational and historical simulated temperature trends from CMIP3 and CMIP5, detection and attribution studies suggested that observed winter warming in East Asia is partly caused by increases in greenhouse gas concentrations (Hu et al. 2003; Wu and Karoly 2007; Wu 2010). However, long-term changes associated with atmospheric internal variability modes, primarily the increasing high index polarity of both the Arctic Oscillation (AO, Thompson et al. 2000) and the hemispheric PNA teleconnection in the second half of the twentieth century, also have induced zonal-mean flow anomalies that contributed to winter warming trends over most Northern Hemisphere (NH) land areas including China (Thompson et al. 2000; Wu and Straus 2004). In contrast, there are tremendous disagreements between models in simulating China's precipitation trends (e.g., Hu et al. 2003). Current CMIP5 coupled models have difficulties in capturing the observed regional precipitation trends in China (Sect. 3.3 and Fig. 8), which makes it difficult to attribute China's current precipitation trends to global warming.

Several studies have found indications of a possible important influence of SST warming over the TIO on wintertime precipitation variations in China in the last few decades. SST over the TIO shows significant warming trends which project well onto the IOB mode since 1960 (Fig. 5a). Through observational analysis and an idealized experiment, Li et al. (2015) found tha the main cause of increasing winter precipitation in the middle and lower Yangtze (MLY) River region in China during 1979-2009 was warming TIO SST. They suggested that enhanced convection generated by TIO SST warming remotely forces an anomalous cyclonic 
Fig. 1 Observed and simulated time series for winters 1960-2014 (winter is DJF starting in the stated year). Observations are averages of about 700 stations in Mainland China, and the Siberia High index is calculated over $70^{\circ}-120^{\circ} \mathrm{E}, 40^{\circ}-60^{\circ} \mathrm{N}$, the box in (d). AMIP (1960-2014) and CMIP5 (1960-2005) lines are ensemble averages described in Sect. 2. a Average SAT anomalies $\left({ }^{\circ} \mathrm{C}\right)$. b Average precipitation anomalies $(\mathrm{mm} /$ month). c Siberia High anomaly index $(\mathrm{hPa})$. d, e, f Winter mean climatology, shown for a basic picture of East Asian winter climate, including (d) NCEP/ NCAR reanalysis SLP $(\mathrm{hPa})$ and vertically integrated water vapor flux (red vectors, Qu, Qv) $[\mathrm{kg} /(\mathrm{m} \mathrm{s})]$. e SAT $\left({ }^{\circ} \mathrm{C}\right)$ and $\mathbf{f}$ precipitation station averages (mm/month)
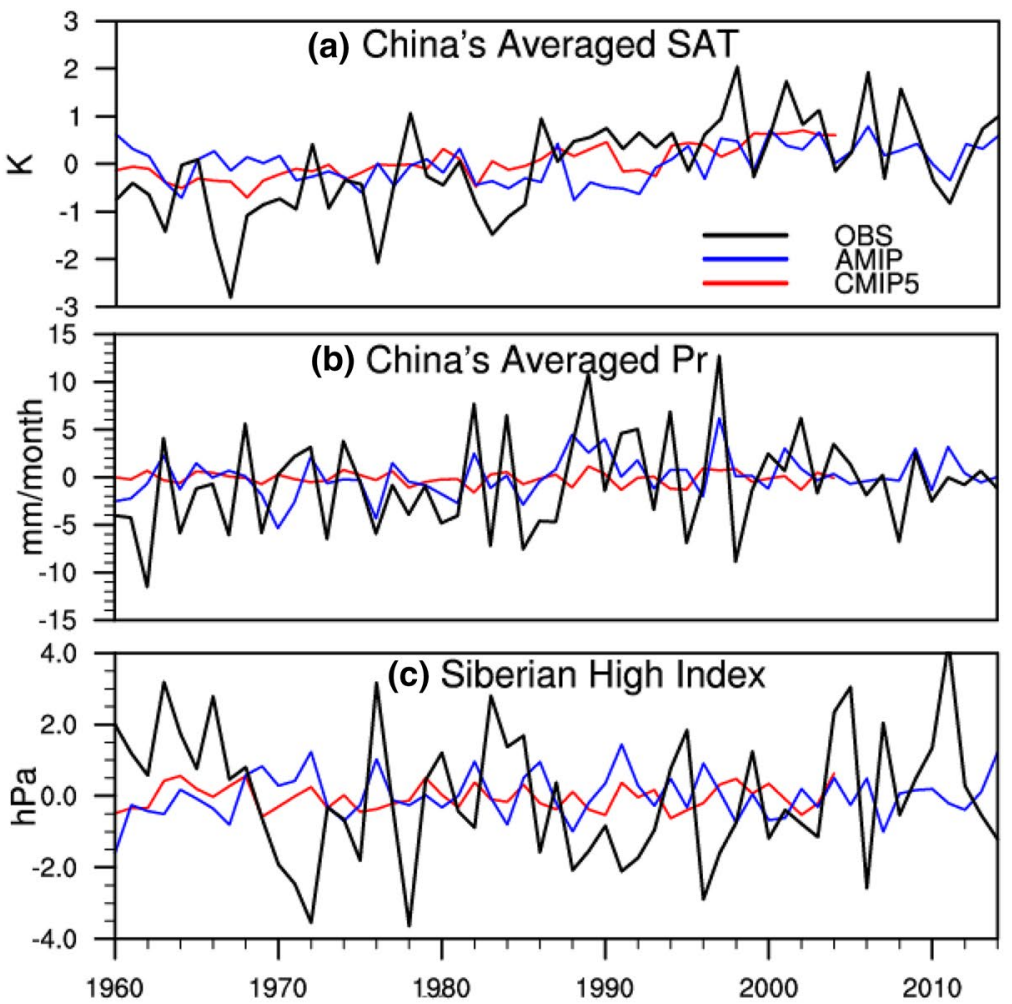

(d) OBS SLP \& (Qu,Qv) Clim

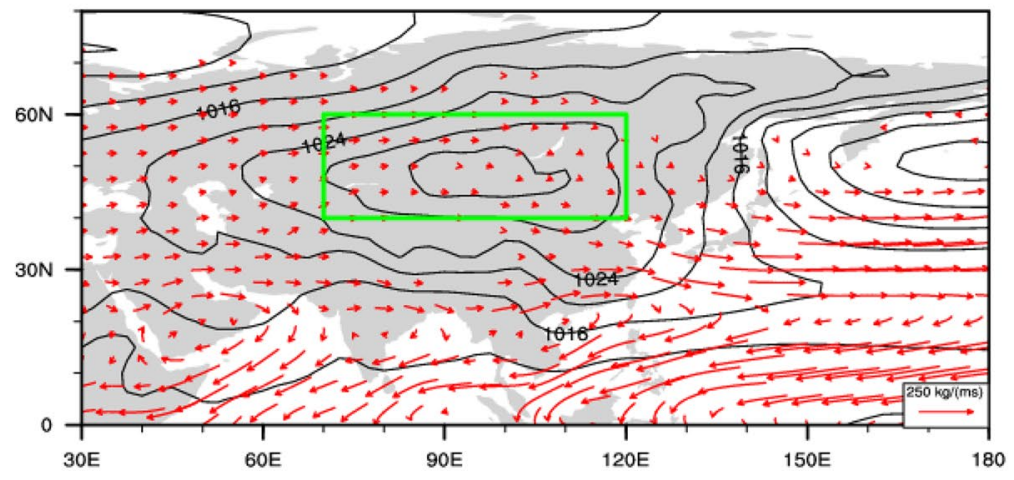

(e) OBS SAT Clim

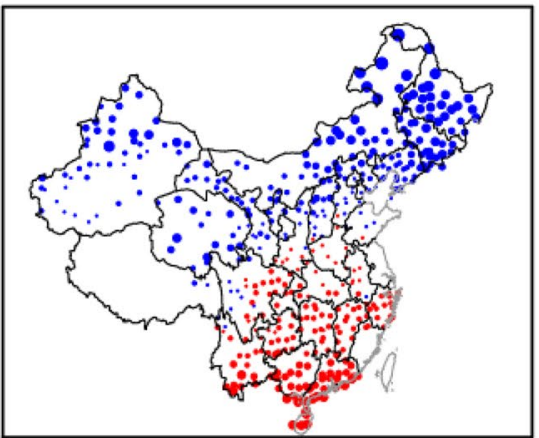

(f) OBS Pr Clim

(e)

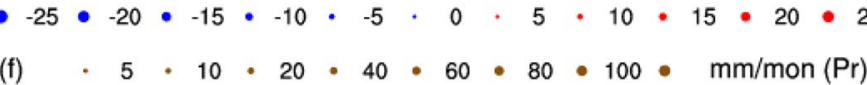


Fig. 2 Winter (DJF) observed linear SAT trends (K/decade) for a 1960-2014, b 1960-1997 and c 1998-2014 at Chinese mainland stations, and $\mathbf{d}, \mathbf{e}, \mathbf{f}$ corresponding simulated ensemble mean trends from AMIP experiments. Solid circles in the top panels and plus symbols in the bottom panels mark individual stations or grid boxes with positive or negative trends significant at the 5\% level (open circles in the top panels are not significant) (a) OBS SAT 60-14

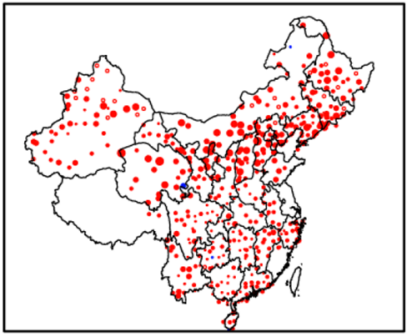

(d) AMIP SAT 60-14

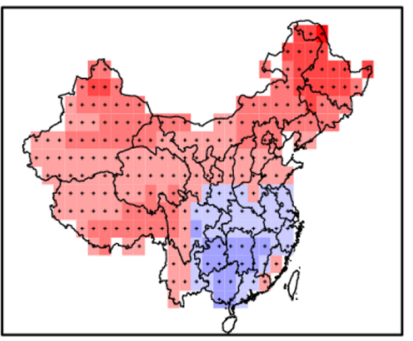

(b) OBS SAT 60-97

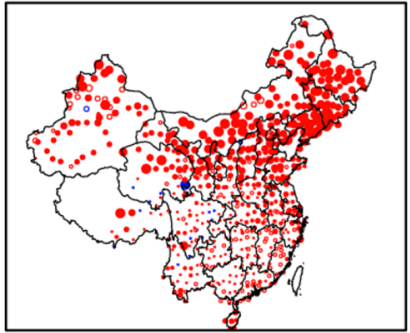

(e) AMIP SAT 60-97

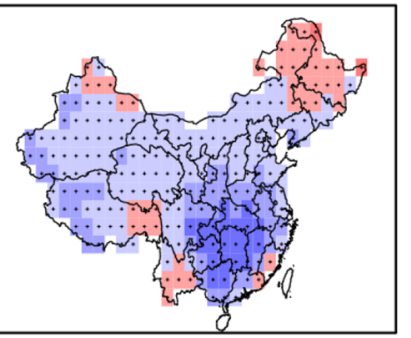

(c) OBS SAT 98-14

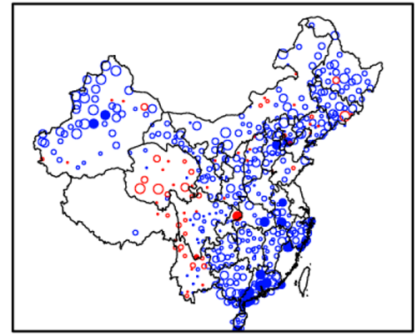

(f) AMIP SAT 98-14

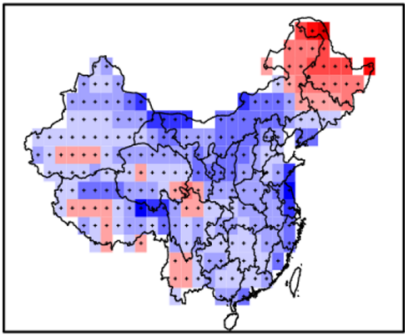

K/decade (SAT)
Fig. 3 Same as Fig. 2 except for winter linear precipitation trends ( $\mathrm{mm} / \mathrm{mon} /$ decade) (a) OBS Pr 60-14

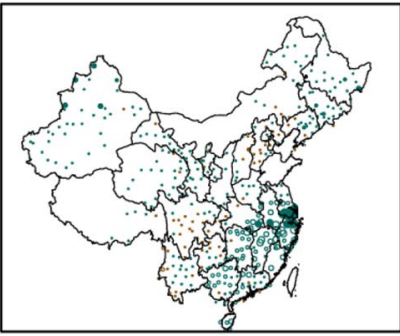

(d) AMIP Pr 60-14

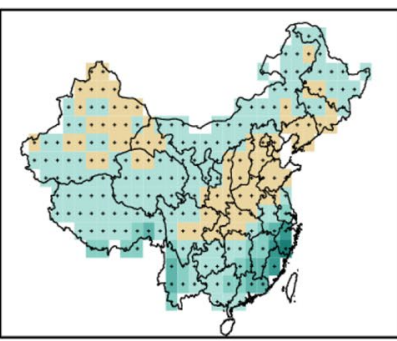

(b) OBS Pr 60-97

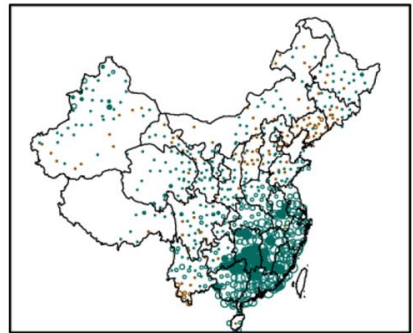

(e) AMIP Pr 60-97

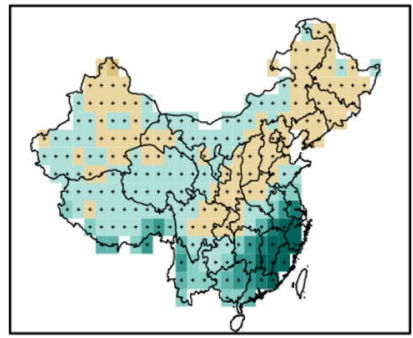

(c) OBS Pr 98-14

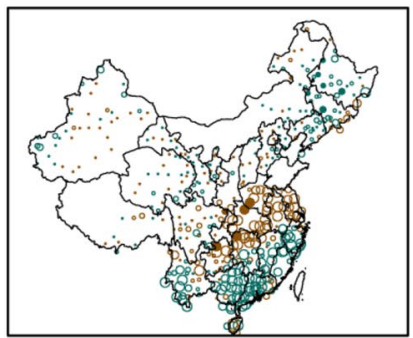

(f) AMIP Pr 98-14

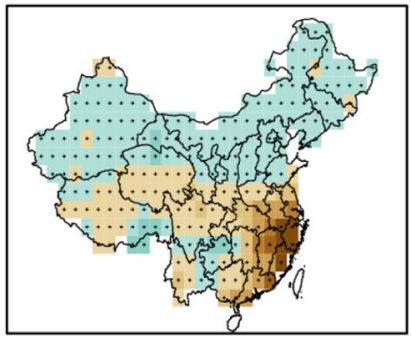

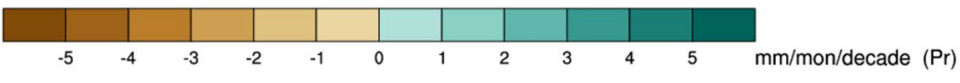

- $-5 \cdot-4 \cdot-3 \cdot-2 \cdot-1 \cdot 0 \cdot 1 \cdot 2 \cdot 3 \cdot 4 \cdot 5 \cdot$ 
circulation along the coast of eastern China, which increases moisture transports to China and causes anomalous convergence over the MLY. Hu et al. (2003) found a high correlation between the leading EOF1 of the TIO SST (resembling the IOB mode) and East China's precipitation and North China's temperature in winter, and suggest that climate variations in winter in China may be connected to the SST warming trend in the Indian Ocean.

The main purpose of this study is to systematically investigate the impacts of global and TIO SST changes on longterm winter temperature and precipitation trends in China since 1960 and the associated mechanisms through analyzing AMIP and coupled historical simulations from CMIP5. Two idealized experiments also isolate and demonstrate important effects of a TIO warming on China winter climate. We examine the whole 1960-2014 period, as well as separate 1960-1997 (weakening EAWM) and 1998-2014 (strengthening EAWM) periods (the exact year of division between EAWM periods is not critical), and focus especially on possible roles of global and TIO SST changes in the observed strengthening EAWM and cold winters since the late 1990s. The findings demonstrate the importance of correct representation of tropical TIO SST changes in coupled models for simulating long-term increasing winter precipitation trends in China. The paper is organized as follows. Data and methods are outlined in Sect. 2, results are presented in Sect. 3, and a summary is provided in Sect. 4.

\section{Datasets and methodology}

In this study, winter (December-February or DJF) is referred to by the starting year and most analyses cover winters 1960-2014, 1960-1997, and 1998-2014, but some datasets are available for other periods as stated. Observation-based datasets include observed monthly temperature and precipitation (Pr) at 700 stations in mainland China for 1960-2014 from the China National Climate Center, precipitation for
1979-2014 from the Climate Prediction Center Merged Analysis of Precipitation (CMAP) (Xie and Arkin 1997), and various atmospheric fields for 1960-2014 from the NCEP Reanalysis (Kalnay et al. 1996). Two indices are used to describe the EAWM, including the intensity of the Siberian High, which is defined as the mean SLP anomaly averaged over the center of climatological Siberian High $\left(70^{\circ}-120^{\circ} \mathrm{E}, 40^{\circ}-60^{\circ} \mathrm{N}\right.$, Fig. 1d) (Gong et al. 2001), and the average temperature anomaly in China.

Table 1 lists three simulated datasets analyzed in this study. The first simulation dataset comprises 52 Atmospheric Model Intercomparison Project (AMIP) historical runs performed by four modeling groups and provided by NOAA Earth System Research Laboratory (ESRL) (http://www. esrl.noaa.gov/psd/). The four ensembles are 12 members from the GEOS 5 model (Molod et al. 2012) simulated by NASA Goddard Space Flight Center (GSFC), 12 members from GFDL AM3 (Donner et al. 2011) by NOAA Geophysical Fluid Dynamics Laboratory (GFDL), and 28 members from CAM5.1 (Neale et al. 2013) by two modeling groups [NOAA ESRL and DOE Lawrence Berkeley National Laboratory (LBNL)]. These four ensembles are chosen because their simulations start before 1960. The atmospheric models are forced by observed well-mixed greenhouse gas concentrations, ozone, aerosols, SST, and sea ice concentration (SIC) (Hurrell et al. 2008). Simulated atmospheric fields of SAT, precipitation, sea level pressure (SLP), $500 \mathrm{hPa}$ geopotential height (Z500), $250 \mathrm{hPa}$ geopotential height (Z250) and 500-hPa wind (UV500) are analyzed during 1960-2014. Most analyses in this study are based on ensemble averages of the 52 runs, but results are very similar if we first took each model's ensemble average and then averaged across the four model ensembles. Therefore, the conclusions are not excessively weighted by CAM5.1. Note that only 40 ensemble members of Z500 and Z250 are analyzed since Z500 and Z250 from GFDL AM3 is not available, and only 28 ensemble members of UV500 are analyzed since UV500 is not available from GEOS 5 and GFDL AM3. Figures 12,
Table 1 Overview of models, including AMIP models and ensemble number for each model, CMIP5 Historical model runs, and model used for the idealized Tropical Indian Ocean observed SST warming (TIOTrend) experiments

\begin{tabular}{|c|c|c|c|c|}
\hline \multirow{2}{*}{$\begin{array}{l}\text { Experiments } \\
\text { AMIP }\end{array}$} & \multicolumn{4}{|l|}{ Model } \\
\hline & $\begin{array}{l}\text { GEOS } 5 \\
(12)\end{array}$ & $\begin{array}{l}\text { ESRL CAM5.1 } \\
\text { (14) }\end{array}$ & $\begin{array}{l}\text { LBNL CAM5.1 } \\
\text { (12) }\end{array}$ & $\begin{array}{l}\text { GFDL AM3 } \\
\text { (12) }\end{array}$ \\
\hline CMIP5 historical & \multicolumn{4}{|c|}{$\begin{array}{l}\text { BCC-CSM1-1, BCC-CSM1-1-m, BNU-ESM, CanESM2, CCSM4, CESM1- } \\
\text { BGC, CESM1-CAM5, CESM1-FASTCHEM, CESM1-WACCM, CMCC- } \\
\text { CESM, CNRM-CM5, CNRM-CM5-2, CSIRO-Mk3-6-0, FGOALS-g2, } \\
\text { FIO-ESM, GISS-E2-H, GISS-E2-H-CC, GISS-E2-R, GISS-E2-R-CC, } \\
\text { INMCM4, MIROC4h, MIROC5, MIROC-ESM, MIROC-ESM-CHEM, } \\
\text { MPI-ESM-LR, MPI-ESM-MR, MPI-ESM-P, MRI-CGCM, MRI-ESM1, } \\
\text { NorESM1-M, and NorESM1-ME (one ensemble for each of } 31 \text { models) }\end{array}$} \\
\hline Idealized TIOTrend & CAM4 & & & \\
\hline
\end{tabular}


$13,14,15,16$ show that most simulated responses to global or TIO SST changes are similar among models, except for limited areas with disagreeing trends in the short 1998-2014 period.

The second simulation dataset is CMIP5 (downloaded through http://cmip-pcmdi.llnl.gov/cmip5/index.html) historical runs forced by observed atmospheric composition changes reflecting both anthropogenic and natural sources (Taylor et al. 2012). These runs use historical forcing from 1850 to 2005, so only 1960-1997 trends are analyzed, but similar results are obtained in 1960-2000 or 1960-2005. To determine the possible roles of external anthropogenic and natural radiative forcings in the observed climate trends, the modeled trends of SST, SAT, precipitation, Z500, and UV500 are calculated. To avoid biasing the multimodel mean towards model versions with large ensembles, only one ensemble member from each of the thirty-one models listed in Table 1 is considered (Taylor et al. 2012). Because CMIP models compute SST and sea ice, they usually do not generate ENSO and other variations in the same years as observed, and ensemble averaging smooths such variations in both time and space.

Significance testing is based on the standard deviation $(\sigma)$ of 55-year (1960-2014), 38-year (1960-1997) or 17-year (1998-2014) linear trends of AMIP ensemble members in any grid box or region, with all members assumed independent. The same $\sigma$ values are assumed to apply when evaluating significance of differences of an observed or reanalyzed trend from zero, or differences of a model trend from the corresponding observed or reanalysis trend. Here we apply a two-sided local significance test (warming trend $\geq 2.0 \sigma$ or cooling trend $\leq-2.0 \sigma$ ) to determine whether the observed trend is significantly different from zero at the 5\% significance level, and whether the simulated trend is significantly different from zero at the 5\% significance level using Itrendl $\geqslant 2.0 \sigma / \sqrt{N-1}$, where $\mathrm{N}$ is the number of ensemble members $(\mathrm{N}=52,40$, or 28$)$. Since the simulated gridded datasets have different horizontal resolutions, they are analyzed after regridding onto a $1^{\circ}$ latitude-longitude grid.

The third simulation dataset in Table 1 is two additional CAM4 (Neale et al. 2013) model runs at T42 spectral resolution, performed by Nanjing University to isolate effects of a TIO warming. The control (CTR) run is forced with monthly climatological SST, and the TIOTrend run is forced with monthly climatological SST plus the monthly observed linear SST warming trend in 1960-2014 over the TIO region (Indian Ocean grid boxes from $20^{\circ} \mathrm{S}$ to $20^{\circ} \mathrm{N}$, reduced linearly to zero amplitude at $30^{\circ} \mathrm{S}$ or $30^{\circ} \mathrm{N}$ to avoid an abrupt discontinuity). The monthly linear SST trend during 1960-2014 is calculated from the data set of Hurrell et al. (2008). Figure 5a shows the DJF trend in K/decade (the 1960-2014 linear trend for any month of the year is 5.5 times the trend in $\mathrm{K} /$ decade). The linear SST trend in the $\mathrm{TIO}$ is approximately equal to is about $1 \mathrm{~K}$ warming. Each run is 60 years long with a repeating annual SST cycle, and the climate response of any variable is the average state from the last 50 years of the TIOTrend run minus the CTR run. Statistical significance of grid-box responses is assessed by a standard two-tailed difference of means Student's t test (Von Storch and Zwiers 1999).

\section{Results}

\subsection{Observed and AMIP trends}

Figure $1 \mathrm{e}-\mathrm{f}$ show the average winter temperature and precipitation in China. The winter temperature averages above $0{ }^{\circ} \mathrm{C}$ in all of southeastern China and winter precipitation averages above $200 \mathrm{~mm}$ (in 3 months) generally in the southeastern coastal region. The main winter water vapor sources are moist air from the southwest over the Indochina Peninsula originating in the TIWP, supplemented by turning flow from the oceans southeast of China (Zhang et al. 2009, Fig. 1d). In winter, the Siberian High (Fig. 1d) brings strong northerly and northeasterly winds over northern and central China and the South China Sea, and its intensity largely determines the strength of the EAWM circulation. Observed China winter SAT shows consistent warming, and the Siberia High index show a negative trend until the late 1990s followed by strong cooling and a recovery of the Siberia High (Fig. 1a, c), both with large interannual fluctuations. In Fig. 2a-c, almost every station shows linear warming trends in 1960-2014 and 1960-1997 (weakening EAWM, averaging $+0.452{ }^{\circ} \mathrm{C} / \mathrm{decade}$, stronger warming north of $40^{\circ} \mathrm{N}$ ), and most stations outside southwestern China show cooling in $1998-2014$ (strengthening EAWM, averaging $-0.513^{\circ} \mathrm{C} /$ decade), which corresponds to the global warming hiatus (Meehl et al. 2011). However, in Fig. 1a the AMIP ensemble mean simulates a slow cooling trend until the early 1990 s, followed by nearly steplike warming $\sim+0.7^{\circ} \mathrm{C}$. In Fig. 2d-f (and in Fig. 12 for all four AMIP ensembles), both 1960-1997 and 1998-2014 show linear warming trends in Northeast China and cooling trends almost everywhere else in China (simulated trends over China average $-0.060{ }^{\circ} \mathrm{C} /$ decade in $1960-1997$ and $-0.066^{\circ} \mathrm{C} /$ decade in $1998-2014$ ), whereas 1960-2014 shows cooling in southeastern China and warming almost everywhere else. This apparent discrepancy can be explained from Fig. 1a (blue line), where the AMIP time series shows general cooling until the early 1990s, a temperature spike peaking in 1999, and some cooling since then. Because the average SAT is warmer after the 1990s than before, the 1960-2014 linear trend shows weak warming even with cooling trends in both sub-periods. The contradictory trends are China averages, so large portions of China in Fig. 2d-f show a similar disagreement with observed station trends. The opposite observed and AMIP 
SAT trends from the 1960s to the late 1990s will be further addressed in Sect. 3.3.

Figure $1 \mathrm{~b}$ shows that observed average winter precipitation increased from 1960 to 1997 (trend $+1.653 \mathrm{~mm} / \mathrm{mon} /$ decade) and also from 1998 to 2014 (+0.225 mm/mon/decade). In Fig. 3a-c, similar trends in both periods in South China result in net increasing precipitation in 1960-2014. The largest drying areas are in the North China plain from 1960 to 1997 and the middle and lower reaches of the Yangtze River from 1998 to 2014. In Fig. 1b, the AMIP ensemble average shows almost the same moistening in 1960-2014 as in the observations with trends of +0.748 and $+0.130 \mathrm{~mm} /$ mon/decade for 1960-1997 and 1998-2014, respectively, including some individual winters with very similar large anomalies, although most winters have small anomalies in AMIP due to ensemble averaging. The correlation between the observed and AMIP ensemble mean precipitation from 1960 to 2014 is +0.52 . The AMIP ensemble-mean simulations (Fig. 3d-f) reproduce the observed precipitation patterns for 1960-2014 and 1960-1997 very well. For the four model ensembles, Fig. 13 shows considerable consistency in linear precipitation trends in South China and the North China plain from 1960 to 2014 and 1960-1997. The consistent AMIP results from 1960 to 1997 and 1960-2014 indicate that global SST changes have contributed to extensive areas of long-term increasing precipitation in South China and decreasing precipitation in the North China plain. In the right column of Fig. 13, although simulated drying trends over coastal East China are consistent among the four ensembles, there are some large disagreements in 1998-2014 trends due to substantial internal atmosphere and ocean variability in that short averaging period. Over South China the ESRL and LBNL CAM5.1 models simulate insignificant positive trends, similar to the observations, while GEOS 5 and GFDL-AM3 simulate drying trends that are mostly insignificant.

The atmospheric circulation changes induced by global SST forcing in the AMIP runs play a central role in simulated winter temperature trends in China. During 1960-2014, significant positive SLP trends are found over eastern Siberia and the western Arctic, and negative SLP trends covering western China and coastal eastern China into the North Pacific (Fig. 4a). Z500 has positive trends almost everywhere, except for two areas with cyclonic trends, one over western China and Central Asia and another over northern Europe (Fig. 4b). In 1960-1997, Fig. 4c shows significant positive SLP trends extending from Siberia to central China and negative SLP trends covering western China, coastal eastern China and the North Pacific, while large-scale significant negative SLP trends are simulated over most regions of the tropical Indian and Pacific Oceans. The positive SLP trends favored stronger surface northerly winds over East Asia and more strongly enhanced the transport of colder air from Siberia into China in 1960-1997 than in the longer period 1960-2014 (Fig. 2d-e). The AMIP ensemble simulates an insignificant positive trend of the Siberian High in 1960-1997 (about $0.160 \mathrm{hPa} /$ decade, blue line in Fig. 1c), but a small and insignificant negative trend in 1968-1997 (about $-0.041 \mathrm{hPa} / \mathrm{decade}$ ), which does not reproduce the significant observed negative trend in 1960-1997 (-0.570 hPa/ decade, black line in Fig. 1c). In Fig. 4d, Z500 has positive trends in most regions of the tropics, reflecting general middle tropospheric warming. This baroclinic tropical atmospheric circulation trend is considered to be a linear dynamical response to SST-related convective heating (Hoskins and Karoly 1981). In addition to a PNA-like pattern in the extratropics, Z500 trends show a "+-+" wave train from the TIO and western Pacific (TIWP) toward eastern Eurasia (EA), which we call the TIWP-EA wave train, with centers over Indonesia, the Tibetan Plateau, and northern Siberia. The TIWP-EA circulation pattern increases the strength of both the trough and the ridge that develops over East Asia during winter, indicating a significant increase in the strength of the EAWM and more frequent cold waves in China in 1960-1997 (Fig. 2e). There is also a clear TIWP-EA response in the Z500 trend in 1960-2014, but with the two northern centers weaker compared to 1960-1997 (Fig. 4b).

During 1998-2014, AMIP simulates strong positive SLP trends with an intensified Siberian High over Northern Eurasia, and from coastal East China to the east of Japan (Fig. 4e), coupled with weak SLP trends over small parts of northern China and Mongolia. Note that the AMIP ensemble generally reproduces the recent recovery of the Siberian High with simulated and observed Siberia High index trends of 0.480 and $0.560 \mathrm{hPa} / \mathrm{decade}$. In Fig. 4f, the Z500 trend also shows the TIWP-EA pattern, but with the northern center stronger and the central cyclonic center much weaker compared to 1960-1997, together with an enhanced Aleutian Low that is part of a distinct positive PNA. This combination of conditions was conducive for cold air intrusions into China, and led to the winter cooling in Fig. 2f. Therefore, the TIWP-EA teleconnection response is a robust feature in the multi-model ensemble mean Z500 trend in all three periods, and displays a mid-latitude barotropic structure in the troposphere. Figure 15 (left column) shows that the ensemble mean Z500 TIWP-EA wave trains agree well among the three available model ensembles.

The above TIWP-EA circulation trends in the AMIP runs have enhanced winter climatological water vapor fluxes from the southwest over the Indochina Peninsula originating in the TIWP and contributed to significantly increased precipitation in South China. As a trough approaches from the west, TIO SST warming favors cyclonic anomalies over western China and anticyclonic anomalies in the subtropical and 
(a) AMIP SLP 60-14

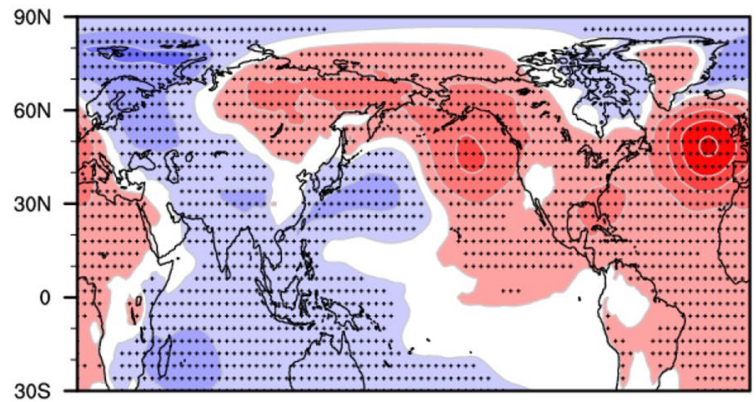

(c) AMIP SLP 60-97

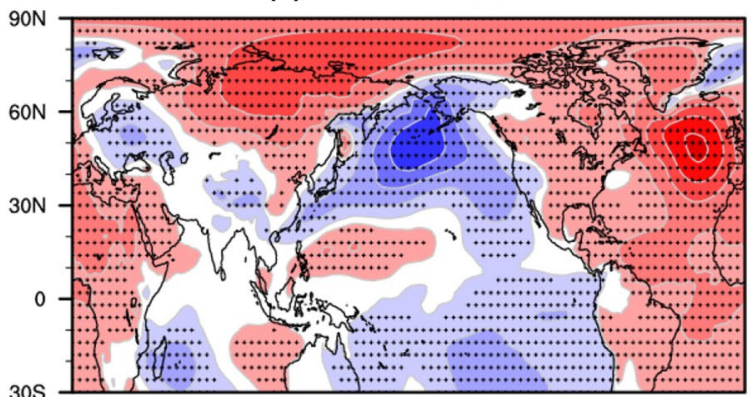

(e) AMIP SLP 98-14

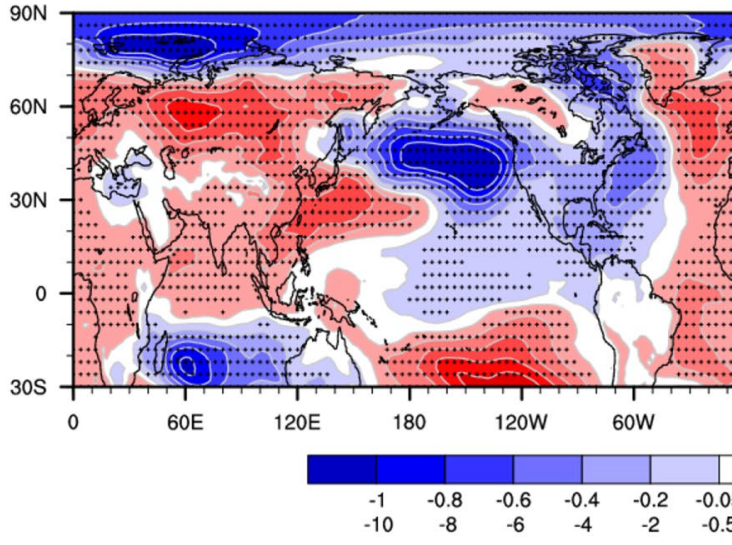

(b) AMIP Z500 60-14

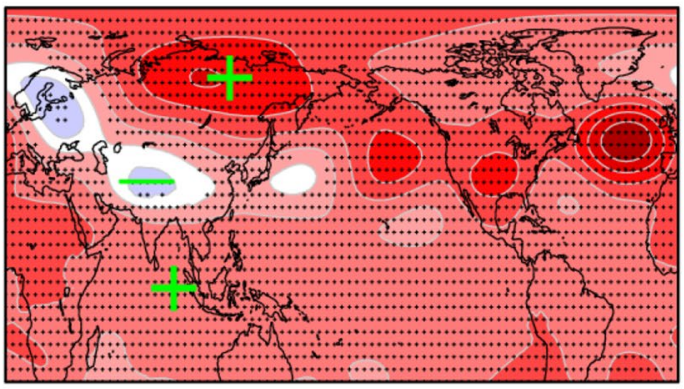

(d) AMIP Z500 60-97

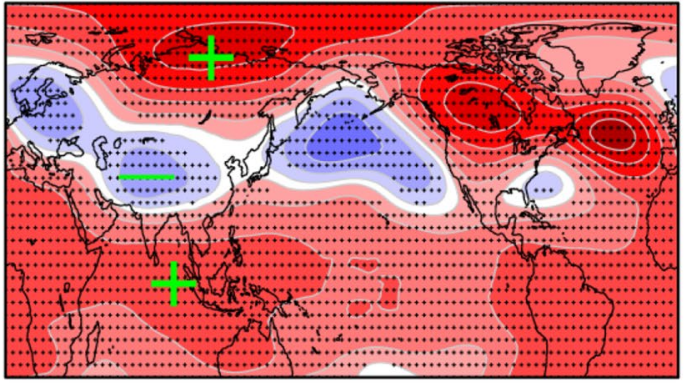

(f) AMIP Z500 98-14

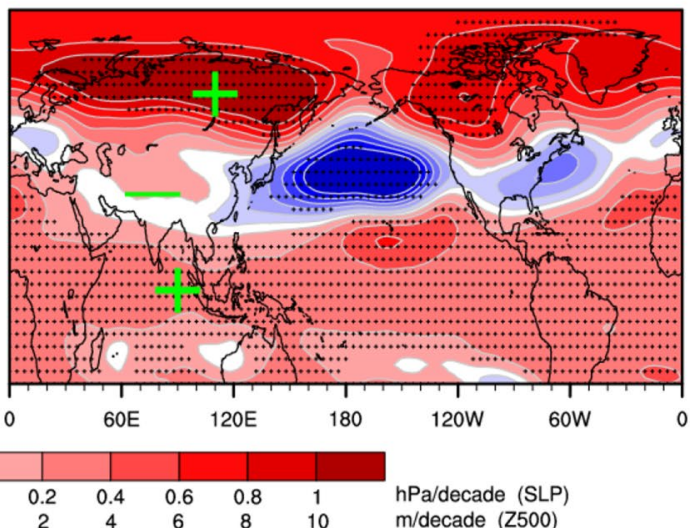

Fig. 4 AMIP ensemble mean winter (DJF) linear trends of (left column) sea level pressure (hPa/decade) and (right column) $500 \mathrm{hPa}$ geopotential height (m/decade) for (top row) 1960-2014, (middle row) 1960-1997 and (bottom row) 1998-2014. Dots mark individual grid boxes with positive/negative trends significant at the $5 \%$ level. The + and - symbols in the right panels are explained in the text. Note that Z500 (b, d, f) is based on ensemble averages of 40 rather than 52 model runs tropical western Pacific (as seen in Fig. 4b, d), enhancing moisture convergence and precipitation especially over the Yangtze region (Fig. 13 of Li et al. 2015). Associated with decreasing Z500 over mid-latitude Asia in the TIWP-EA teleconnection responses in Fig. 4, southwesterly flow ahead of the southern branch of westerly troughs is enhanced, and troughs over China continually strengthen from 1960 to 1997 (Fig. 16a). The continuing positive Z500 trend in the western subtropical Pacific indicates a strengthened and northward displaced subtropical high. These Z500 trends led to an increasing southerly water vapor transport into southern China and favored large-scale persistent winter precipitation events (including freezing rain when this moisture overruns a shallow subfreezing air mass) over southern China.

During 1998-2014, the TIWP-EA teleconnection response in Fig. 4f (also Fig. 15f, i) and the associated UV500 trend (Fig. 16b) also contribute to forced increased precipitation in South China in ESRL CAM5.1 and LBNL CAM5.1 (Fig. 13c, f, i). However, the PNA-like responses play a major role in drying trends over coastal East China 
(a) OBS SST Trend 60-14

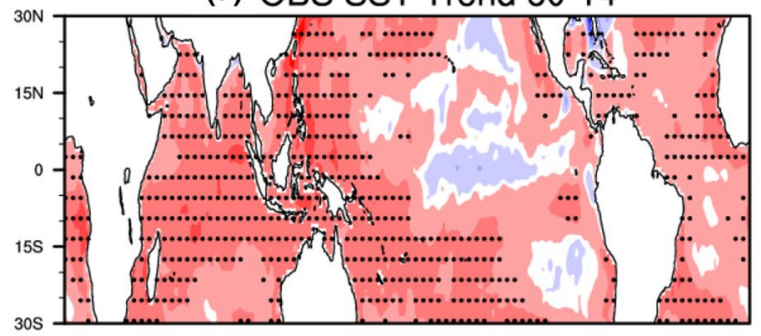

(c) OBS SST Trend 60-97

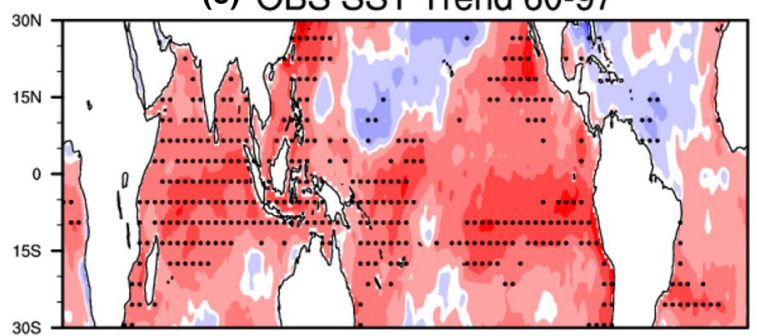

(e) OBS SST Trend 98-14

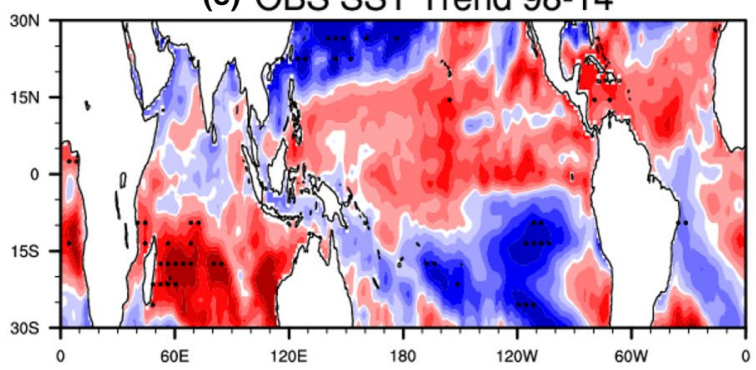

$$
30
$$

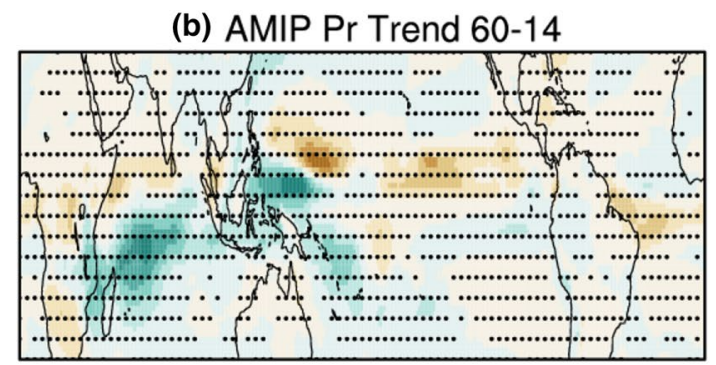

(d) AMIP Pr Trend 60-97

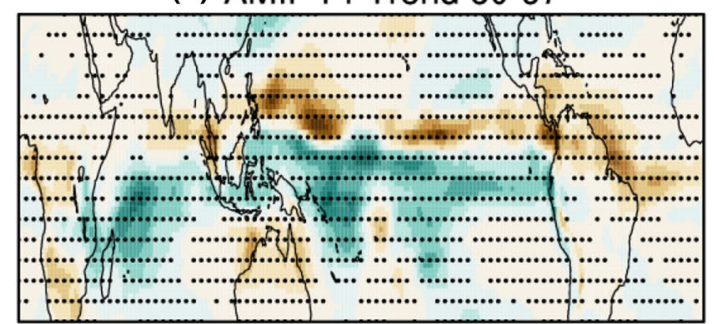

(f) AMIP Pr Trend 98-14

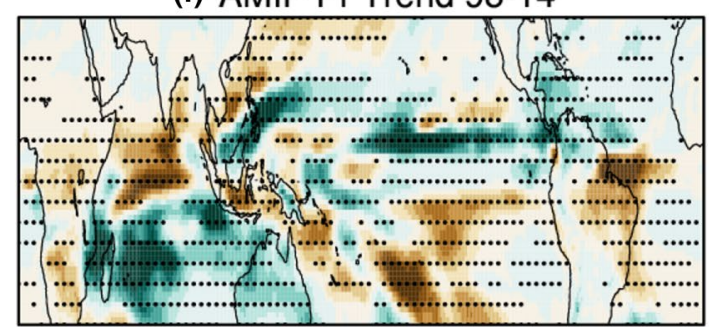

(g) OBS Pr Trend 98-14

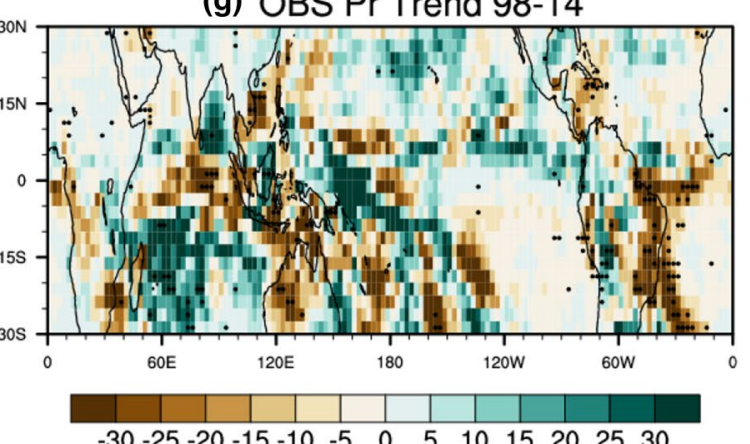

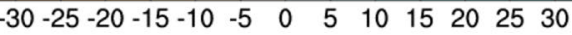

$\mathrm{mm} / \mathrm{mon} /$ decade
Fig. 5 (Left column) observed winter (DJF) SST linear trends (K/ decade) (a, c, e) and (right column) AMIP ensemble mean winter linear trends of tropical precipitation $(\mathrm{mm} / \mathrm{mon} /$ decade), for (top row) 1960-2014, (second row) 1960-1997 and (third row) 1998-2014.
Observed CMAP precipitation trends during 1998-2014 are plotted in (g). Dots mark individual grid boxes with positive/negative trends significant at the $5 \%$ level in the ensemble mean and three of the four models (GEOS 5, ESRL CAM5.1 and LBNL CAM5.1). The negative Z500 trends over the North Pacific induced northerly or northeast wind trends over East China (Fig. 16b), which led to a decreasing southerly water vapor transport into East China and were unfavorable to large-scale persistent winter precipitation.
The physical link by which tropical forcing affects extratropical atmospheric circulation involves diabatic heating anomalies caused by tropical rainfall changes (Hoskins and Karoly 1981). In Fig. 5c, significant warming SST is detected over the eastern Tropical Pacific during 1960-1997, along with increased precipitation over the central and eastern equatorial Pacific (Fig. 5d). The associated diabatic heating contributes to the PNA-like response in Fig. $4 \mathrm{~d}$ 
(Trenberth et al. 1998). Similarly, during 1998-2014 (Fig. 5e) strong SST warming over the central and eastern equatorial Pacific and northern subtropical Pacific caused significant increased precipitation over the northern East Tropical Pacific (Fig. 5f), which is responsible for an even larger PNA response in that period (Fig. 4f). In Fig. 5b, d, $\mathrm{f}$, the AMIP experiment simulates consistently increased precipitation over the southern Indian Ocean during all three periods (1960-2014, 1960-1997 and 1998-2014), but increased precipitation over most of the equatorial
Fig. 6 a Winter (DJF) simulated (red, based on AMIP) and observed (blue, based on CMAP) precipitation indices (standard deviations) calculated over boxes in the tropical Indian Ocean (in b: $50-90^{\circ} \mathrm{E}$, $0-20^{\circ} \mathrm{S}$, in c: $40-90^{\circ} \mathrm{E}, 0-20^{\circ} \mathrm{S}$ ). b-i Regressions of simulated or observed $(\mathbf{b}, \mathbf{c})$ precipitation, (d, e) SLP, (f, g) Z500 and (h, i) Z250 onto the corresponding TIO precipitation index in (a). Panels $(\mathbf{b}, \mathbf{d}, \mathbf{f}, \mathbf{h})$ are based on AMIP simulated ensemble averages during 1960-2014, panels $(\mathbf{c}, \mathbf{e}, \mathbf{g}, \mathbf{i})$ are based on observations during 1979-2014, and Z500 and Z250 are based on ensemble averages of 40 rather than 52 model runs. Dots mark individual grid boxes with precipitation, SLP, Z500 or Z250 regression coefficients significant at the 5\% level. The + and - symbols in panels $\mathbf{f}-\mathbf{i}$ are explained in the text (a) TIO Precipitation indices

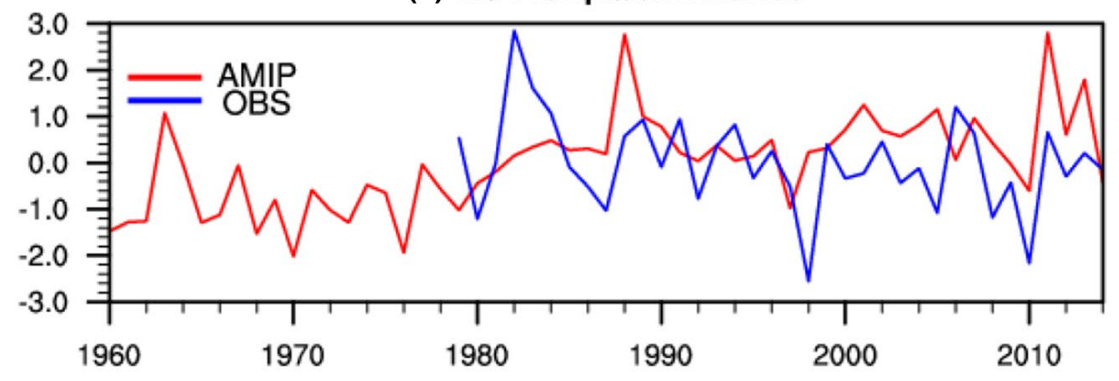

(b) AMIP Precipitation (1960-2014)

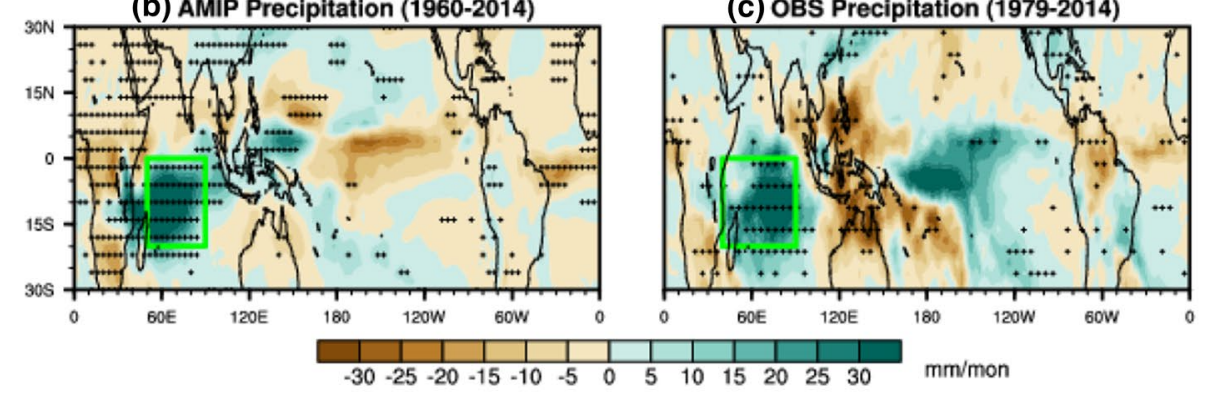

(d) AMIP SLP (1960-2014)

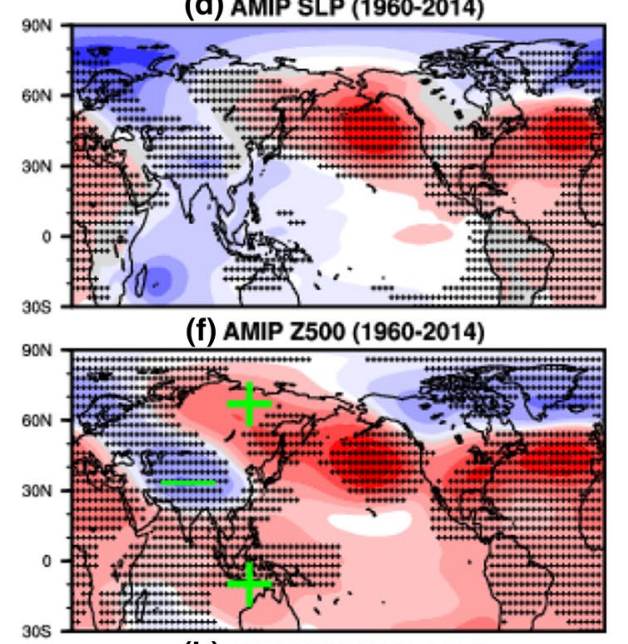

(h) AMIP Z250 (1960-2014)

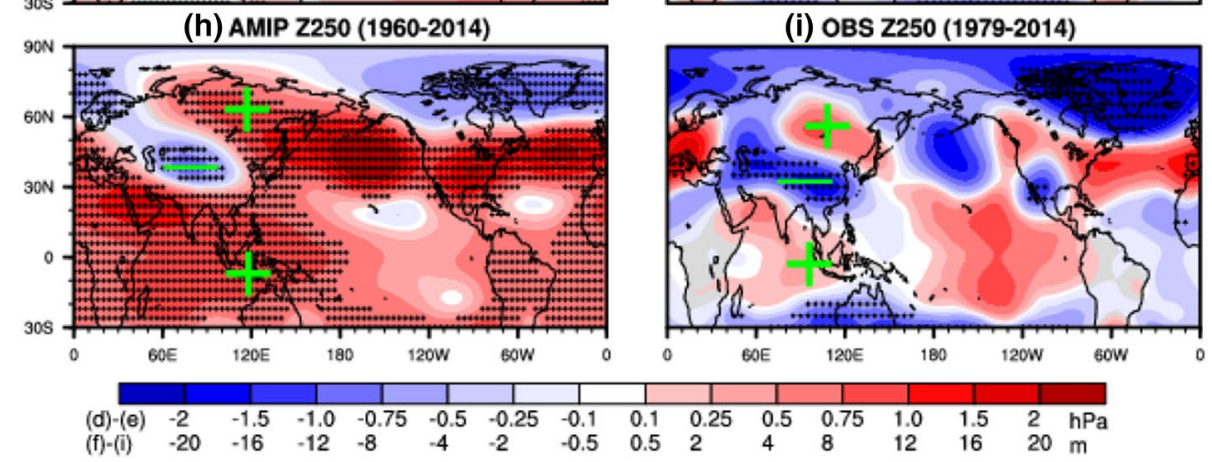

(e) OBS SLP (1979-2014)

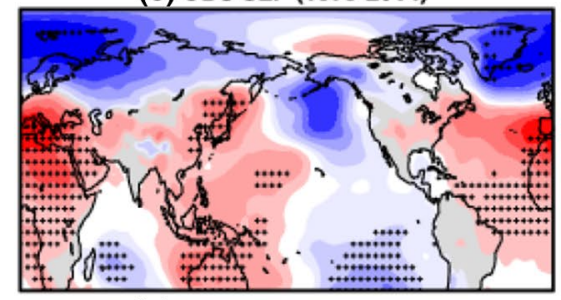

(g) OBS Z500 (1979-2014)

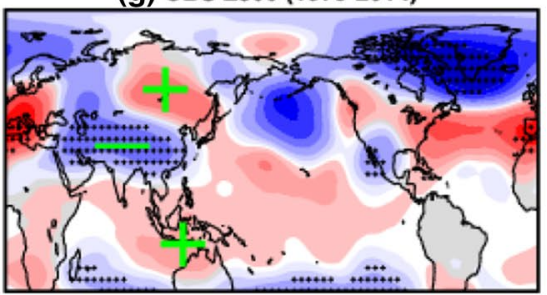

(i) OBS Z250 (1979-2014) 
Indian Ocean during 1960-2014 and 1960-1997, and decreased precipitation in 1998-2014. The above precipitation responses over the TIO are consistent with significant SST warming over the whole TIO basin which projects onto the IOB mode during 1960-2014 and 1960-1997, and only over the southern TIO during 1998-2014 (Fig. 5a, c, e). The AMIP ensemble mean increased (decreased) precipitation over the southern (equatorial) Indian Ocean is remarkably consistent with that in the observed (OBS) CMAP data during 1998-2014 (Fig. 5f-g).

To examine the potential role of the TIO rainfall increase in driving winter circulation trend patterns over eastern Eurasia, we constructed two normalized TIO precipitation indices averaging the precipitation anomaly over areas with large TIO precipitation trends in the AMIP simulation and observational CMAP data (Fig. 6a). Then, we calculated regression maps of AMIP precipitation, SLP, Z500 and $\mathrm{Z} 250$ onto the corresponding normalized TIO precipitation index (Fig. 6b-c). The regression maps show Z500 responses to wet (versus dry) seasons even though trends and specific extreme seasons differ in each source. The AMIP regressed precipitation anomaly (Fig. 6b) reveals a maximum increase in TIO rainfall from about $40^{\circ} \mathrm{E}-80^{\circ} \mathrm{E}$, closely resembling the positive TIO rainfall trend patterns in the AMIP simulations (Fig. 5a, c). SLP regression patterns show significant negative anomalies over the TIO in both AMIP and observations, and significant negative anomalies over central Asia in AMIP (Fig. 6d-e). The AMIP Z500 regression map (Fig. 6f) strongly resembles the TIWP-EA trend patterns over Asia in Fig. 4d, f. Similar correspondence is also found in 1979-2014 between the observed TIO precipitation anomaly and the NCEP reanalysis Z500 anomaly. The TIWP-EA wave train in the upper troposphere is strengthened and displays a barotropic structure (Fig. 6h-i). Figure $6 \mathrm{~d}-\mathrm{i}$ suggest that the TIWP-EA wave train and associated atmospheric circulation anomalies can also be triggered by observed winter rainfall anomalies over the TIO. Figure 17 shows TIO precipitation indices, precipitation trends, and Z500 anomaly patterns computed in the same way for each of the three model ensembles with available Z500 outputs. The simulated TIWP-EA teleconnection agrees well with observations (Fig. 6) and also among three available models (Fig. 17), indicating that this is very likely a real atmospheric teleconnection in spite of the differences between AMIP and observed trends.

During 1998-2014, decreased precipitation over most of the equatorial and northern Indian Ocean triggers a negative TIWP-EA wave train, which partly offsets the positive TIWP-EA wave train induced by increased precipitation over the southern Indian Ocean in the AMIP experiment simulations (Fig. 5f). This explains why the cyclonic center over Asia during 1998-2014 in Fig. 4e-f is much weaker than during 1960-1997.

\subsection{Results in the idealized experiments}

The above AMIP results suggest that the increasing DJF TIO rainfall trend is an important factor in Asian climate change. This advances the physical argument for a link between TIO precipitation forcing and the observed extratropical response over the Asian region (Zheng et al. 2013; Li et al. 2015). We further verify this relationship using an idealized CAM4 model experiment forced with observed Indian Ocean warming trends in 1960-2014 (TIOTrend) and climatological SST elsewhere, as described in Sect. 2. The atmospheric response to observed SST warming only in the TIO is calculated as the 50-year average state of the TIOTrend run minus the CTR run. Figure 7 displays responses in DJF of SAT, land and oceanic rainfall, SLP, Z500, Z250 and $850 \mathrm{hPa}$ wind vectors and the vertically integrated water vapor flux with this idealized Indian Ocean SST warming. A cooling response over the China mainland and a positive precipitation response in South China are clearly simulated (Fig. 7a, b). SLP shows negative anomalies over the Indian Ocean and most of Eurasia, and a large positive anomaly over northeast Eurasia and the extratropical North Pacific (Fig. 7c). The Z500 and Z250 response (Fig. 7d, e) over the TIO and western Pacific and Asia virtually replicates the TIWP-EA patterns in Figs. 4b, d and $6 \mathrm{e}-\mathrm{i}$. The positive precipitation response in South China is obviously due to enhanced southwesterly flow and moisture convergence into southeastern China associated with decreasing Z500 over mid-latitude Asia in the TIWP-EA pattern and the strengthened subtropical high (Fig. 7b-f). Note that the Z500 response pattern over the North Atlantic projects strongly onto the positive polarity of the NAO pattern, consistent with Hoerling et al. (2004).

\subsection{Results in coupled simulations from CMIP5 in 1960-1997}

Figure 8 shows the 31-model ensemble-mean trends of winter SAT and precipitation in China during 1960-1997 from CMIP5 historical runs. The external forcing leads to general warming over mainland China, with linear SAT trends of $+0.10-0.20(0.20-0.30){ }^{\circ} \mathrm{C} /$ decade over southern (northern) China. These are much weaker than observed warming trends in Fig. 2b. The CMIP5 ensemble mean trend of China's averaged SAT is $0.165^{\circ} \mathrm{C} /$ decade, compared to the observed value of $0.452{ }^{\circ} \mathrm{C} /$ decade (Fig. 1a). Similarly, the CMIP5 simulates a small negative trend of the Siberia High in 1960-1997 (-0.030 hPa/decade) (Fig. 1c, red line). The CMIP5 ensemble mean in Fig. 1a reproduces the China winter SAT trend at about one-third of the smoothed observed amplitude, and with small annual variations because ensemble members independently simulate phenomena such as ENSO and the Pacific Decadal Oscillation (PDO) including their SST variations. Meanwhile, reduced precipitation over 
(a) SAT

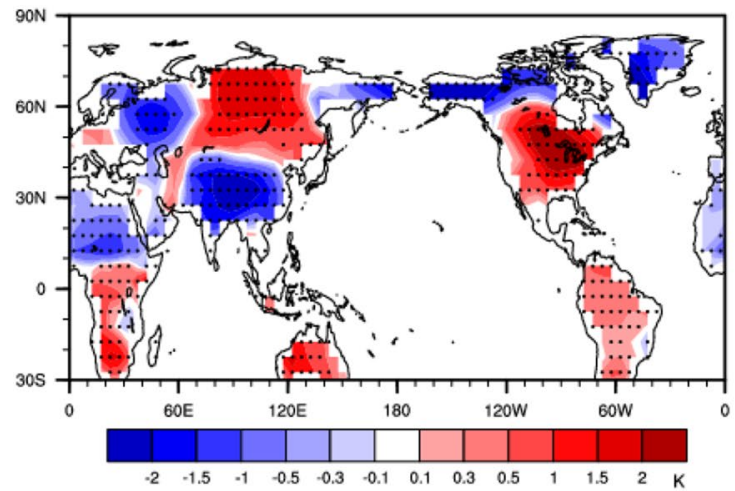

(c) SLP

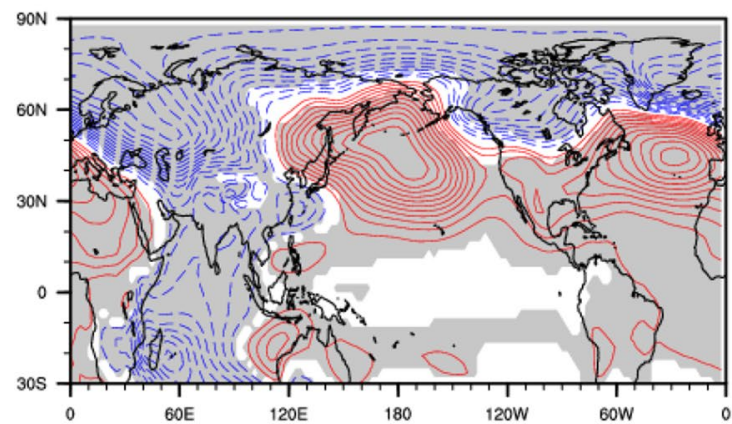

(e) $Z 250$

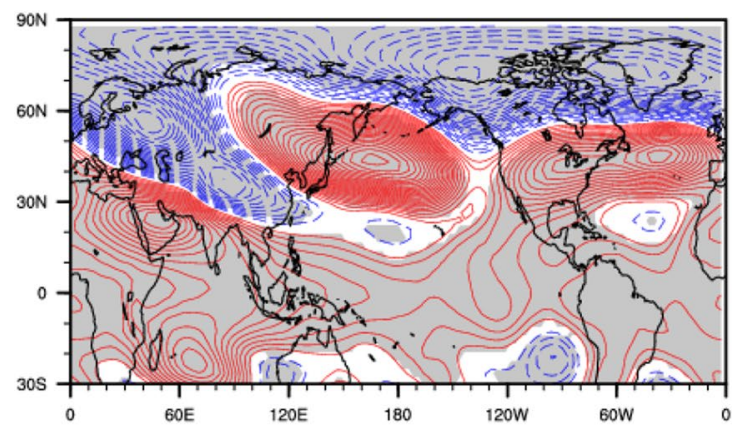

Fig. 7 Simulated winter (DJF) responses to observed SST warming in the TIO in 1960-2014 based on the last 50 years of 60-year CAM4 runs (TIOTrend minus CTL): a SAT (K), b precipitation ( $\mathrm{mm} / \mathrm{month}$ ) and vertically integrated water vapor flux (red vectors, $\mathrm{Qu}, \mathrm{Qv}$ ) $[\mathrm{kg} /$ ( $\mathrm{m} \mathrm{s}$ ), vectors plotted only if $>5 \mathrm{~kg} / \mathrm{m} \mathrm{s}$ )], c SLP, d Z500, e Z250, and f $850 \mathrm{hPa}$ wind vectors (arrow indicates $5 \mathrm{~m} / \mathrm{sec}$ ). Contour intervals are $0.5 \mathrm{mb}$ for SLP and $5 \mathrm{~m}$ for Z500 and Z250. Negative contours (b) $\operatorname{Pr} \&(Q u, Q v)$

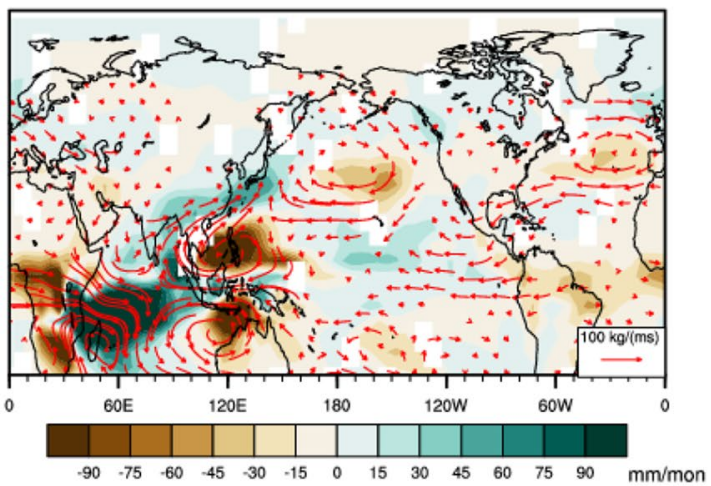

(d) $Z 500$

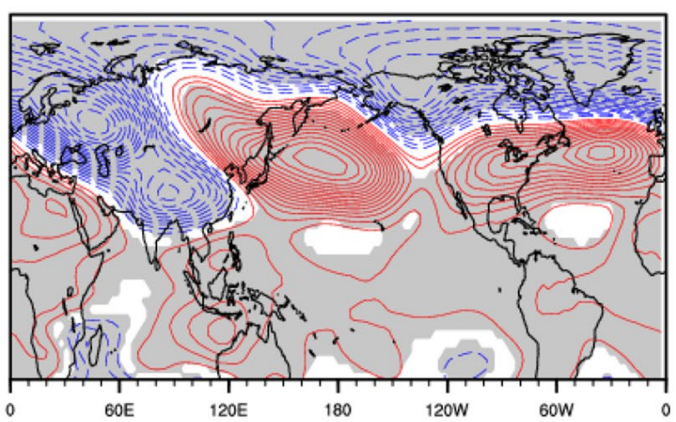

(f) $850 \mathrm{hPa}$ wind

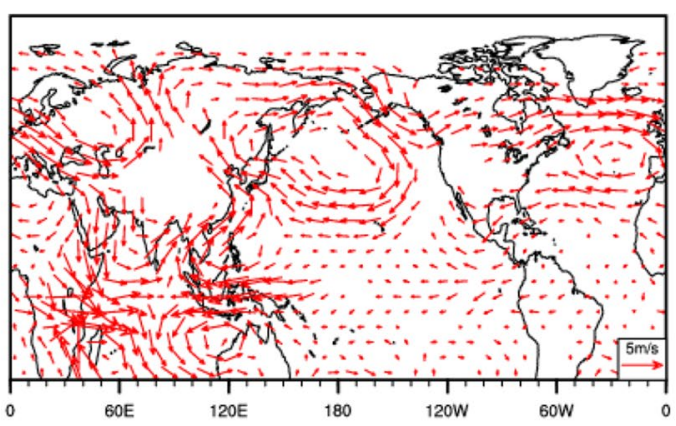

are dashed, zero line omitted in (c-e). Dots in (a) and gray shading in (c-e) mark individual grid boxes with positive/negative responses significant at the 5\% level. In (b), only precipitation and water vapor flux vector responses significant at the 5\% level are plotted. In (f), only vectors are plotted with significant responses of $850 \mathrm{hPa}$ zonal and/or meridional wind speed at the $5 \%$ level

ensemble mean, but missed in the CMIP5 Historical ensemble runs.

In Fig. 9, NCEP reanalysis Z500 trends for 1960-1997 show large decreases over northern Eurasia and the Arctic (significant mainly around Greenland), but significant increases over most of Asia south of $50^{\circ} \mathrm{N}$. The pattern of polar decreasing heights and mid-latitude increasing heights indicates a tendency toward a high AO index 
Fig. 8 CMIP5 ensemble mean winter (DJF) 1960-1997 linear trends of a SAT (K/decade) and b precipitation $(\mathrm{mm} / \mathrm{mon} / \mathrm{dec}-$ ade). Dots mark individual grid boxes with positive or negative trends significant at the 5\% level (a) CMIP5 SAT Trend 60-97
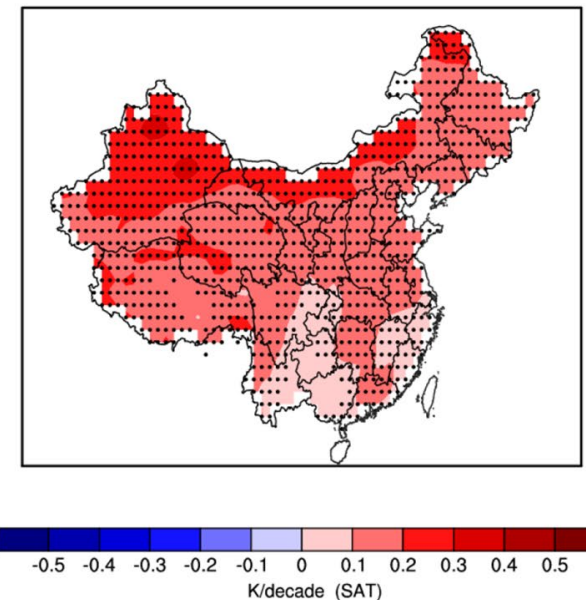

(b) CMIP5 Pr Trend 60-97
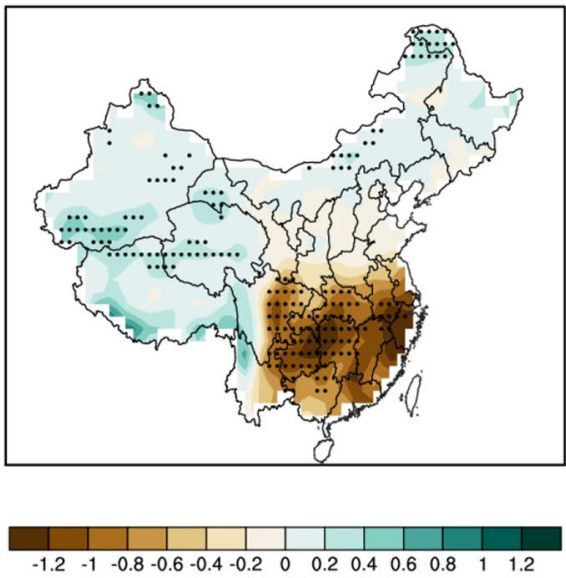
$\mathrm{mm} / \mathrm{mon} /$ decade $(\mathrm{Pr})$ (a) NCEP Z500 60-97

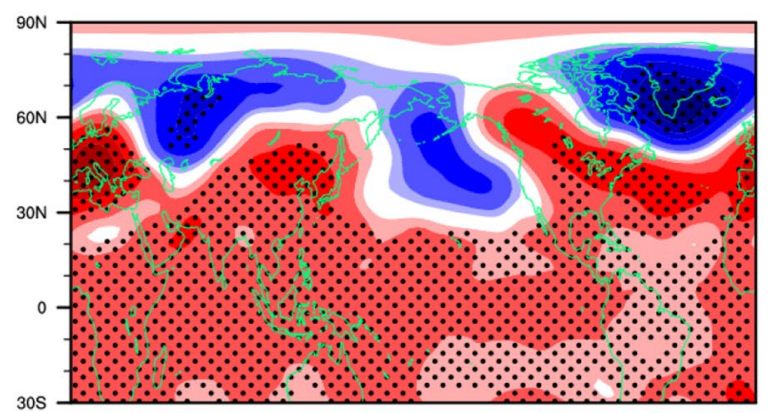

(c) NCEP Z500 98-14

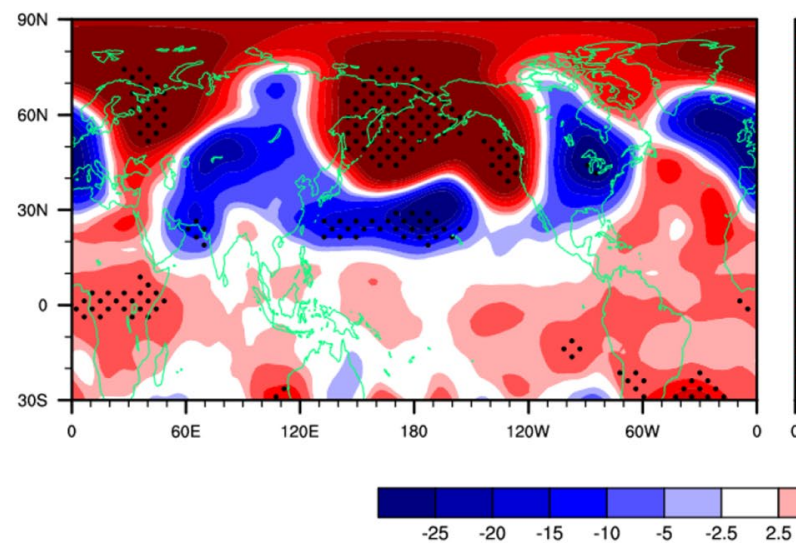

(b) NCEP UV500 60-97

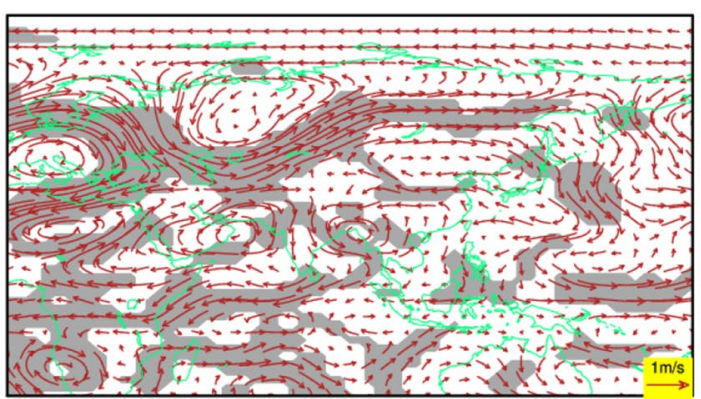

(d) NCEP UV500 98-14

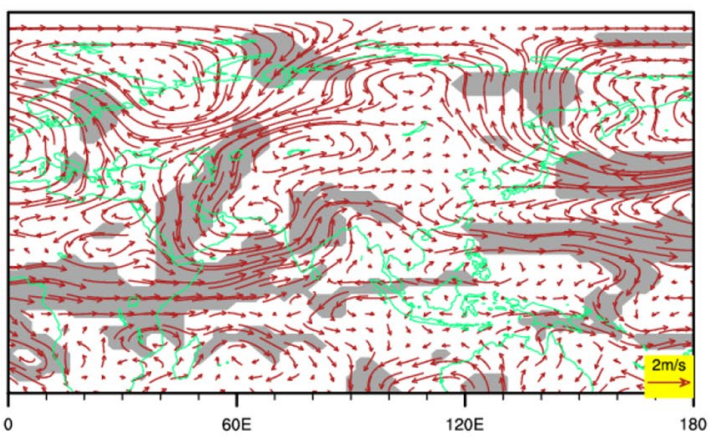

180
Fig. 9 NCEP reanalysis DJF (a, b) 1960-1997 and (c, d) 1998-2014 linear trends of $(\mathbf{a}, \mathbf{c}) 500-\mathrm{hPa}$ geopotential height $(\mathrm{m} / \mathrm{decade}$, dots mark grid boxes with positive or negative trends significant at the $5 \%$ level), and (b, d) 500-hPa wind vectors (m/sec/decade). In (b, d), gray shaded areas have trends of 500-hPa zonal and/or meridional wind speed significant at the 5\% level, and the arrow in the yellow box indicates the magnitude of the specified wind anomaly polarity (Thompson et al. 2000). The resulting circulation changes favored weaker northerly winds over East Asia and reduced transport of cold air from Siberia into China, leading to observed warming winter SAT in China. This is in contrast to the AMIP cooling trend induced by the TIWPEA teleconnection. Comparing Figs. $4 d$ and $9 a$, the AMIP ensemble mean obviously does not reproduce the observed Z500 trend pattern. However, Fig. 9a, b show an area with a 
(a) CMIP5 Z500 60-97

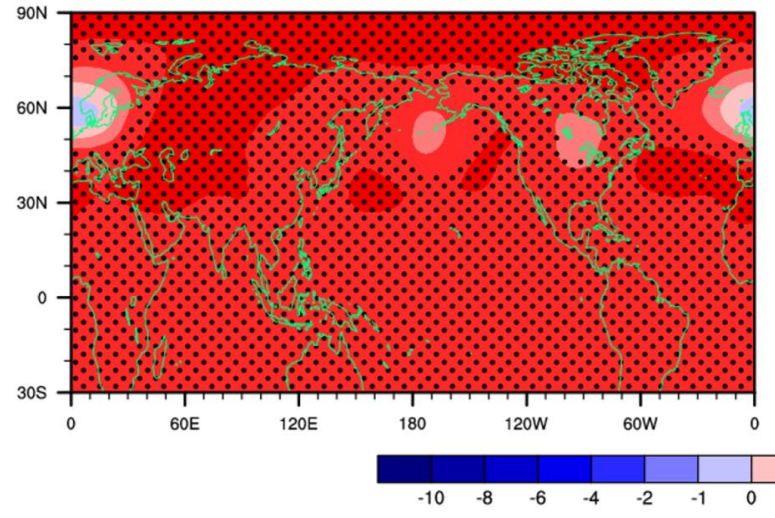

(c) CMIP5 SST 60-97

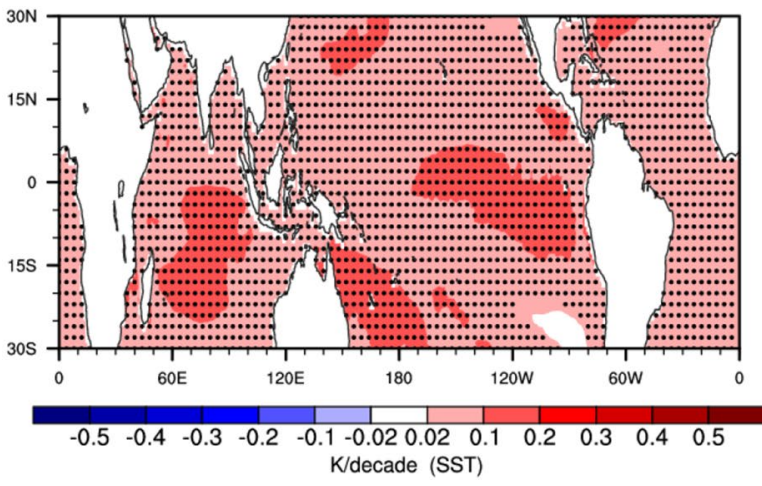

Fig. 10 CMIP5 ensemble mean winter (DJF) 1960-1997 linear trends of a $500-\mathrm{hPa}$ geopotential height (m/decade), b 500-hPa wind vectors $(\mathrm{m} / \mathrm{sec} / \mathrm{decade})$, c SST (K/decade) and $\mathbf{d}$ tropical precipitation $(\mathrm{mm} / \mathrm{mon} /$ decade). Dots mark individual grid boxes with positive or (b) CMIP5 UV500 60-97

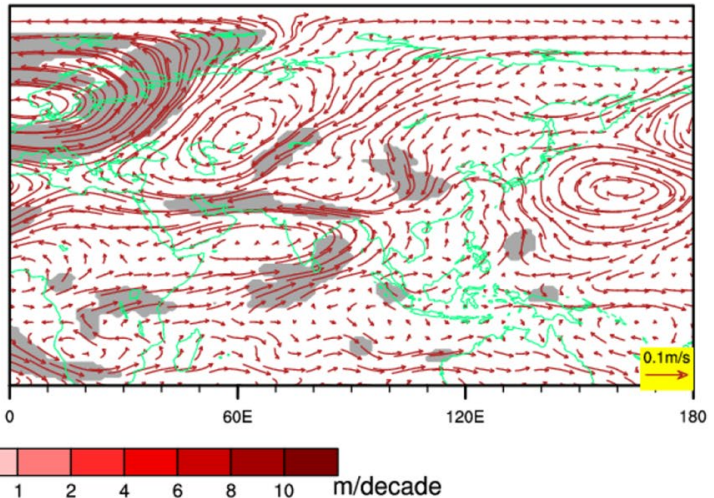

(d) CMIP5 Pr 60-97

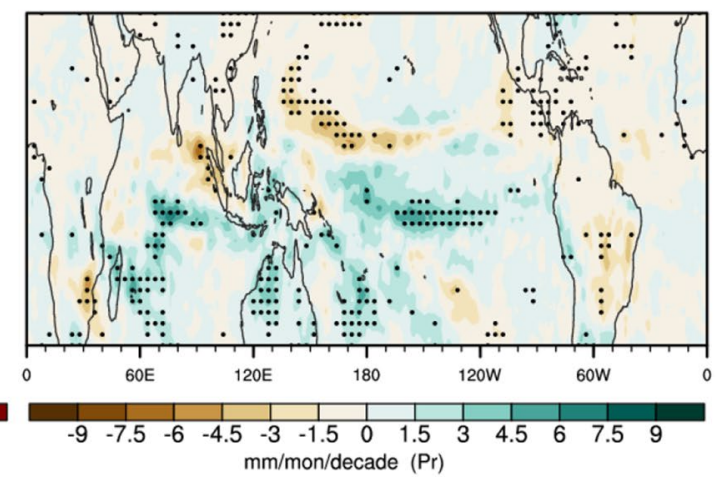

negative trends significant at the 5\% level in (a, c-d). Gray shaded areas have significant trends of 500-hPa zonal and/or meridional wind speed at the $5 \%$ level in (b)

warming by the atmospheric circulation is quite small and the AO-induced warming in the observations in Fig. 9a is not simulated in the CMIP5 simulations, which partially explains why observed and simulated SAT trends in Figs. $2 \mathrm{~b}$ and $8 \mathrm{a}$ differ. On the other hand, associated with the above Z500 trend in Fig. 10a, CMIP5 historical runs simulate anticyclonic wind trends over East Asia and the North Pacific (Fig. 10b). In Fig. 10c, CMIP5 reproduces general tropical SST warming (including TIO warming), but with reduced magnitude (and no cooling areas) compared to observations in Fig. 5c. The CMIP5 precipitation trends, in particular over the TIO, are also much weaker than in the AMIP simulations (Fig. 5d). In Fig. 10a, CMIP5 does not reproduce the TIWP-EA wave train at all. Previous studies indicate the importance of the correct representation of tropical SST changes for simulating regional land warming and precipitation trends (Shin and Sardeshmukh 2011). This possibly explains why current CMIP5 coupled models have 
difficulties in capturing the observed regional precipitation trends in China.

From the results in CMIP5 only, it is questionable to attribute China's current precipitation trends primarily to global warming. However, Fig. 10c reproduces observed TIO SST warming in 1960-1997, although with reduced magnitude compared to observations in Fig. 5c, suggesting that the anthropogenic-induced greenhouse gas concentration increase contributes toward the TIO warming during that period. Several studies have reported similar greenhouse gas contributions to the observed TIO warming since 1950 (Hoerling et al. 2004; Knutson et al. 2013; Chan and Wu 2015). Therefore, we conclude that the ongoing greenhouse gas concentration increase has significantly contributed to the long-term increase in winter precipitation in South China, through its direct contribution to increasing TIO warming, and also by the indirect mechanism of dynamical oceanic forcing of Asian climate change induced by TIO SST warming.

\section{Conclusions and discussion}

In 1960-1997 and 1960-2014, observational winter SAT trends show linear warming over almost all of China, a weakened Siberia High, and increased precipitation especially in South China. In 1998-2014, trends show slight cooling except in southwestern China and a strengthened Siberia High, and some moistening especially in South China except for decreased precipitation in the middle and lower reaches of the Yangtze River. The AMIP ensemble shows cooling trends over China except for warming in Northeast China in 1960-1997 and 1998-2014, but warming over China except for cooling in Southeast China in the whole 1960-2014 period. However, AMIP generally reproduces the observed increasing precipitation trend patterns over South China in the 1960-1997 and 1960-2014 periods.

Trends of 500-hPa height and other variables in AMIP ensemble averages show two wave trains that lead to winter circulation changes around China. The first, from the western North Pacific and across North America, resembles a well-known positive PNA and is induced primarily by equatorial eastern Pacific SST warming and its resulting enhanced convective heating during 1960-1997 and 1998-2014 (Trenberth et al. 1998). The other wave train is a persistent TIWP-EA teleconnection emitted from the TIO and western Pacific (increased Z500) toward Siberia, with reduced Z500 over central Asia and enhanced Z500 over Siberia. The TIWP-EA teleconnection displays a barotropic structure with increased SLP over Siberia and decreasing SLP over most of China. Both observations and AMIP simulation data suggest that the TIWP-EA wave train is mainly triggered by TIO SST warming and the resulting enhanced

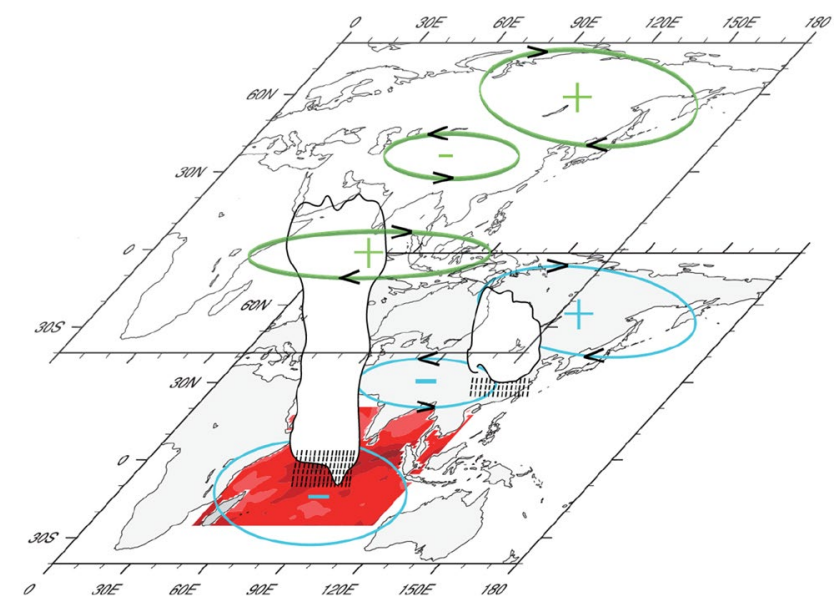

Fig. 11 Two-layer schematic representation of the winter precipitation increase in South China caused by the TIO warming since 1960 (SST warming pattern in defined TIO region shown in red). The upper layer (free troposphere) shows the TIWP teleconnection by "+" and "-", symbols, and bright green ovals denote the TIWP anticyclonic and cyclonic 500-hPa circulation anomalies. The lower layer (surface and boundary layer) shows the corresponding structure on the surface in blue ovals with negative sea level pressure anomalies over the tropical Indian Ocean, and also over central Asia (similar to Figs. 4a, 7c), and a positive SLP anomaly over eastern Siberia. As a primarily barotropic structure, the TIWP extends through most of the troposphere, and to higher altitudes in the tropics than in high latitudes

convection and increased winter rainfall anomalies. During 1960-1997, the TIWP-EA teleconnection is the primary mechanism for long-term increasing precipitation in South China, explaining why each of the available AMIP ensemble-mean simulations satisfactorily reproduces the observed precipitation patterns. Figure 11 shows a schematic mechanism of long-term increasing precipitation trends in South China induced by the TIO warming.

During 1998-2014, the TIWP-EA wave train is seen in both the AMIP ensemble mean Z500 trend (Fig. 4f) and the NCEP reanalyzed Z500 trend (Fig. 9c). Strong SST warming over the southern TIO induces strong increased precipitation in the same area (Fig. 5g). Such TIO diabatic heating contributes to the Z500 and $500 \mathrm{hPa}$ wind trends in Fig. 9c, $\mathrm{d}$ by inducing the TIWP-EA wave train (Fig. $6 \mathrm{f}, \mathrm{h}$ ), and is inferred to be an important contributor to the observed winter precipitation increase over most of South China during 1998-2014. In the observations (Fig. 9d), the anomalous northeast wind associated with the significant negative Z500 trend over the subtropical Pacific is restrained over the middle and lower reaches of the Yangtze River and induces a drying trend in this region. However, in the AMIP ensemble mean, a negative Z500 trend associated with a PNA anomaly pattern extends into East China while a positive Z500 trend associated with the TIWP-EA is simulated over West China (Fig. 4f). 
Associated with the above Z500 trend, a drying northerly wind trend is simulated over all of East China (Fig. 16b). In this short 17 -year period, the more southerly location of TIO warming, the strong warming in the equatorial and subtropical North Pacific (compared to 1960-1997), and substantial internal atmospheric and other SST variability may explain differing locations and magnitudes of precipitation trends over South China in observations and AMIP models.

Although previous studies have recognized that China's winter climate changes can be driven by TIO forcing (e.g., Hu et al. 2003; Yang et al. 2010; Wang et al. 2010; Li et al. 2015), we build on these studies through comparisons of observed and simulated precipitation responses and trends, and attribute long-term trends of China's precipitation in winter to specific mechanisms including a newly-identified TIWP-EA wave train, which is especially enhanced by TIO SST warming. This proves that progressive TIO warming, which projects well onto the IOB mode, has been an important contributor to climate changes in China since 1960. The idealized simulation with observed SST warming only in the TIO, which produces a TIWP-EA wave train and China winter SLP, SAT, and precipitation responses almost identical to observations, supports the contention that TIO diabatic heating is an important contributor to the observed winter precipitation increase over South China. Detection and attribution studies indicate that global and TIO SST warming since 1950 is anthropogenically induced by rising greenhouse gas concentrations (Hoerling et al. 2004; Knutson et al. 2013; Chan and Wu 2015). Therefore, it is very likely that the observed winter precipitation increase over south China is attributed to global warming due to rising greenhouse gas concentrations. Because the TIO SST and greenhouse gases are projected to further increase in the coming decades (Kirtman et al. 2013), the increasing winter precipitation trend in South China is very likely to continue.

During 1998-2014, the AMIP ensemble generally reproduces the observed strengthening EAWM (including the intensified Siberian High and China's cold winters), which should be partially attributed to the response to those SST and SIC changes. Arctic sea ice has been declining in boreal autumn and winter during recent decades (Vaughan et al. 2013). Observational and simulation studies demonstrate that the Arctic sea ice decline can induce a negative AO response (Wu and Zhang 2010; Liu et al. 2012; Kim et al. 2014) and a strengthened Siberian High and East Asian trough (Wu et al. 2011, 2015; Zuo et al. 2016), and thus a cold Eurasia winter (Mori et al. 2014; Wu et al. 2015; Zuo et al. 2016). The AMIP ensemble results in 1998-2014 support the hypothesis that Arctic sea ice loss might partly contribute to a recent recovery of Siberia High and cold winters in China (Gao et al. 2015; Wu et al. 2015; Zuo et al. 2016). Meanwhile, the TIWP-EA wave train, including the anticyclonic anomaly from Siberia into East Central China and cyclonic anomaly over inland
China, suggests that both TIO warming and Arctic sea ice decline might contribute to recent extreme winter events such as unusually severe cold surges and prolonged ice storms in South China in 2008, 2013 and 2016 (Ding et al. 2014).

CMIP5 historical runs also indicate that external anthropogenic (including increasing greenhouse gas concentrations) and natural forcings have contributed to the generally weakened EAWM and China winter warming from 1960 to 1997. Simulated trend patterns of SST and precipitation over oceans are qualitatively similar to observed trends, but their values are much smaller than the corresponding observed values almost everywhere, in particular over the TIO. Ensemble mean 500-hPa wind vectors show an anticyclonic trend from 1960 to 1997 over the entire eastern China, leading to a drying trend throughout South China that does not match with observations. This suggests that CMIP5 models have difficulties in simulating realistic oceanic changes and resulting regional atmospheric responses. On the other hand, although AMIP ensemble mean simulated Z500 trend patterns do not reproduce all observed Z500 trends, especially the observed Arctic Z500 decrease with three troughs over central Russia, the North Pacific, and around Greenland, AMIP still reproduces cyclonic wind trends over South and East Asia associated with the TIWP-EA teleconnection originating from the TIO and thus the observed increasing precipitation in southern China. This highlights the importance of correct model representation of SST changes for simulating China's precipitation trends, and also indicates that the TIO plays an important role in the long-term and interannual variations of China's winter precipitation in reality.

Acknowledgements We are grateful for the insightful and constructive comments from two anonymous reviewers. We thank four modelling groups for performing AMIP experiments and ESRL for making model outputs available through their web site at http://www.esrl.noaa.gov/ psd/repository/. This work is funded by the National Key Scientific Research Plan of China (Grant 2012CB956002) and the National Natural Science Foundation of China (Grant 41075052 and 41375076), and also supported by the Jiangsu Collaborative Innovation Center for Climate Change and CMA-NJU Joint Laboratory for Climate Prediction Studies. The numerical calculations in this paper have been done on the Blade cluster system in the High Performance Computing \& Massive Data Center (HPC\&MDC) of School of Atmospheric Sciences, Nanjing University.

Open Access This article is distributed under the terms of the Creative Commons Attribution 4.0 International License (http://creativecommons.org/licenses/by/4.0/), which permits unrestricted use, distribution, and reproduction in any medium, provided you give appropriate credit to the original author(s) and the source, provide a link to the Creative Commons license, and indicate if changes were made.

\section{Appendix}

See Figs. 12, 13, 14, 15, 16 and 17. 
Fig. 12 Winter (DJF) simulated ensemble means of linear SAT trends (K/decade) for (left column) 1960-2014, (middle column) 1960-1997, and (right column) 1998-2014. Rows from top to bottom are from GEOS 5, ESRL CAM5.1, LBNL CAM5.1, and GFDL AM3 models (a) GEOS 5 60-14

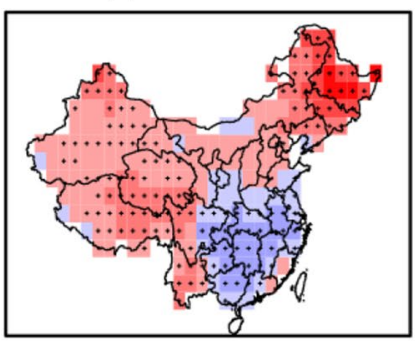

(d) ESRL CAM5.1 60-14

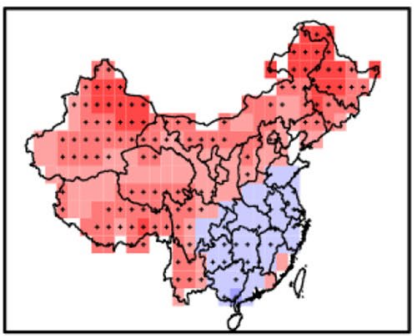

(g) LBNL CAM5.1 60-14

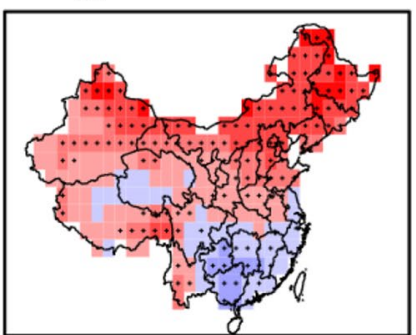

(j) GFDL AM3 60-14

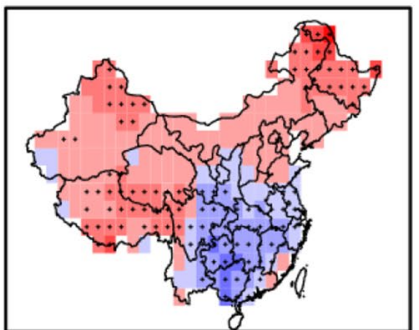

(b) GEOS 5 60-97

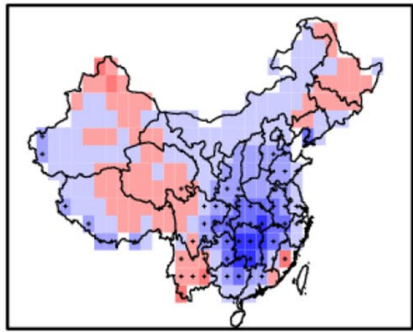

(e) ESRL CAM5.1 60-97

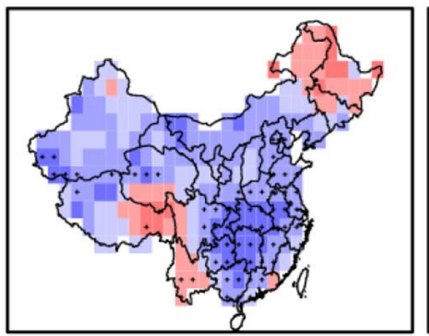

(h) LBNL CAM5.1 60-97

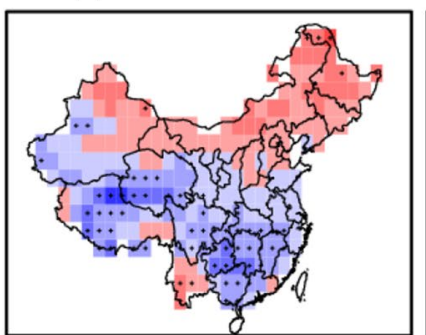

(k) GFDL AM3 60-97

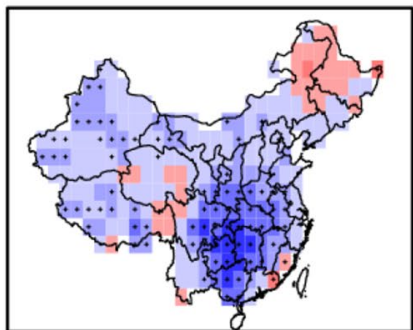

(c) GEOS 5 98-14

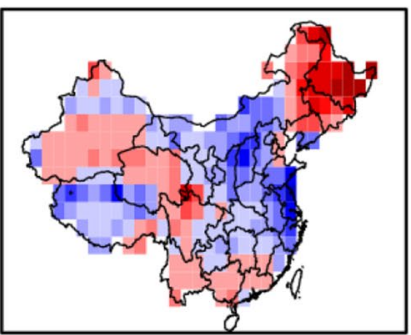

(f) ESRL CAM5.1 98-14

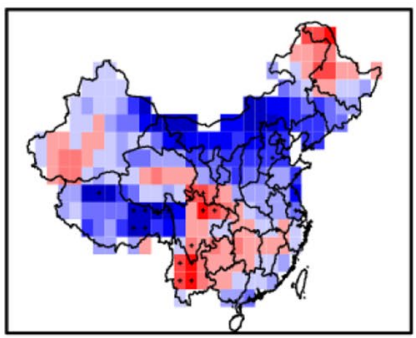

(i) LBNL CAM5.1 98-14

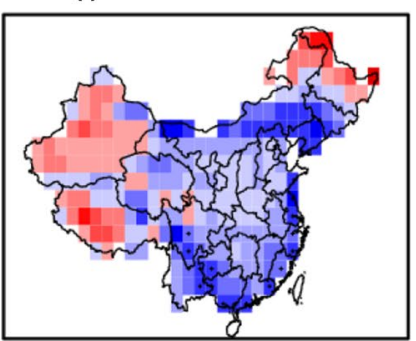

(I) GFDL AM3 98-14

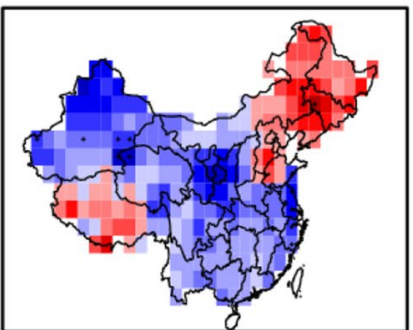

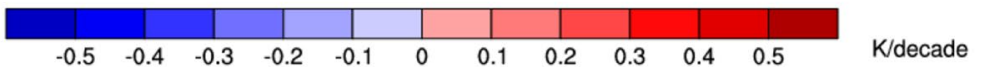


Fig. 13 Same as Fig 12 but for winter (DJF) simulated ensemble means of linear precipitation trends ( $\mathrm{mm} / \mathrm{mon} /$ decade) (a) GEOS 5 60-14

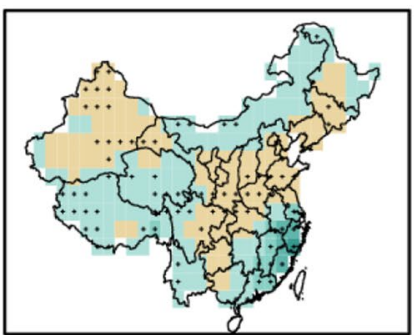

(d) ESRL CAM5.1 60-14

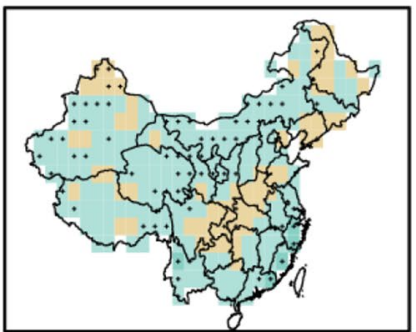

(g) LBNL CAM5.1 60-14

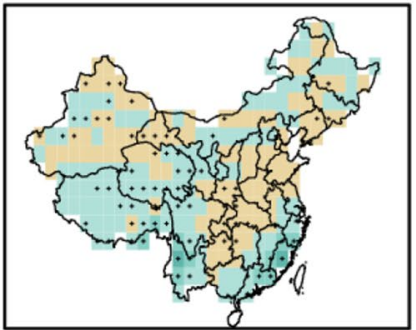

(j) GFDL AM3 60-14

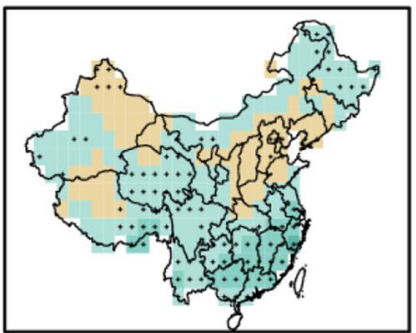

(b) GEOS 5 60-97

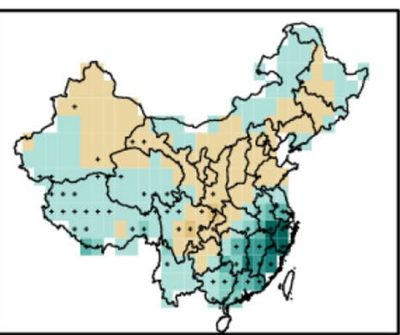

(e) ESRL CAM5.1 60-97

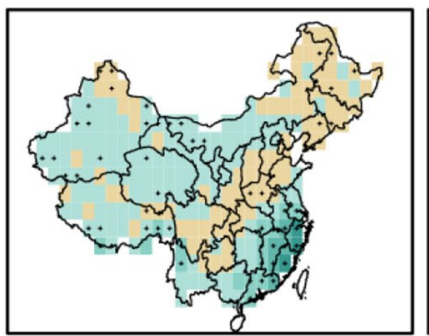

(h) LBNL CAM5.1 60-97

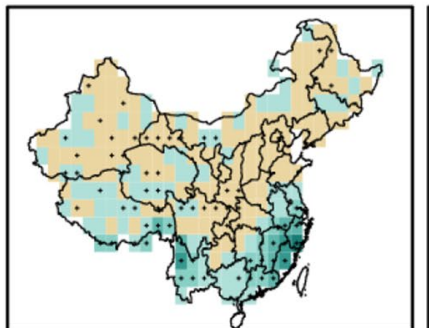

(k) GFDL AM3 60-97

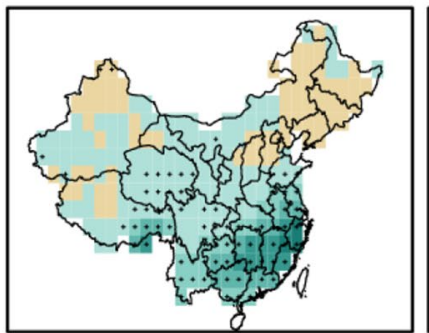

(c) GEOS 5 98-14

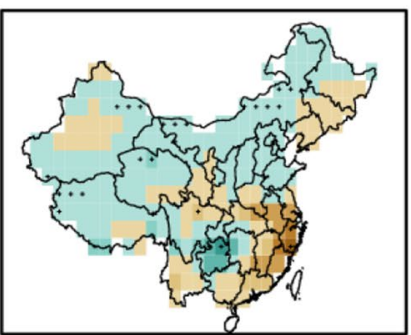

(f) ESRL CAM5.1 98-14

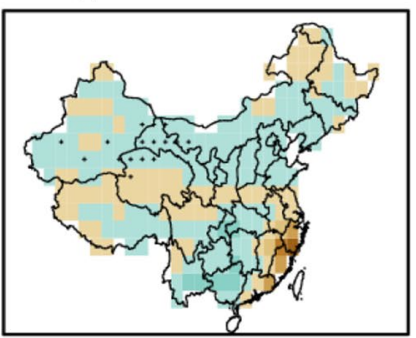

(i) LBNL CAM5.1 98-14

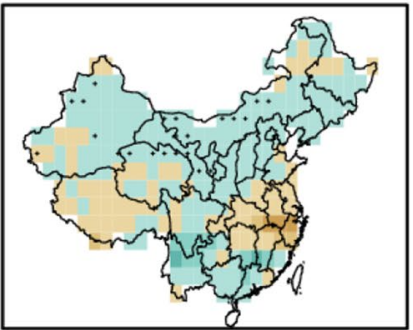

(I) GFDL AM3 98-14

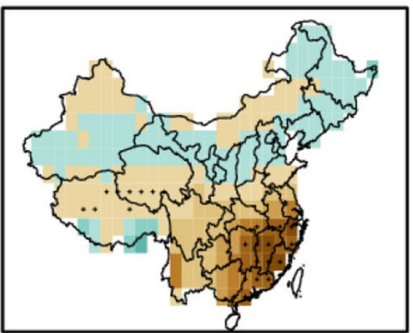

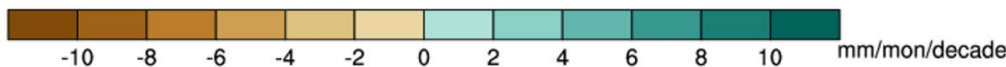


(a) GEOS 5 60-14

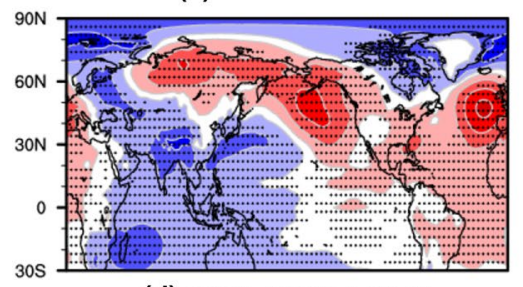

(d) ESRL CAM5.1 60-14

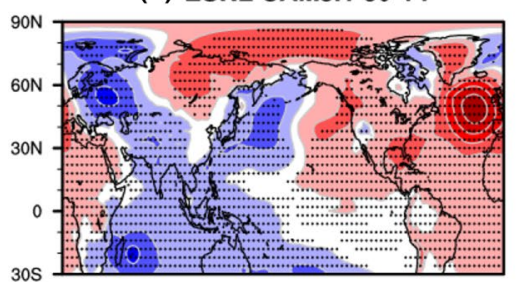

(g) LBNL CAM5.1 60-14

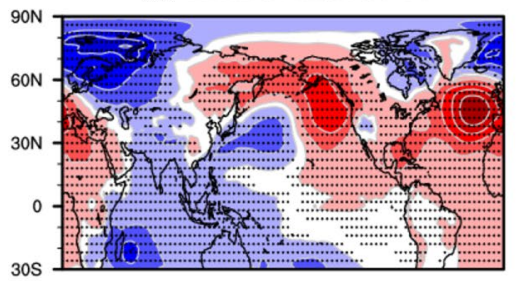

(j) GFDL AM3 60-14

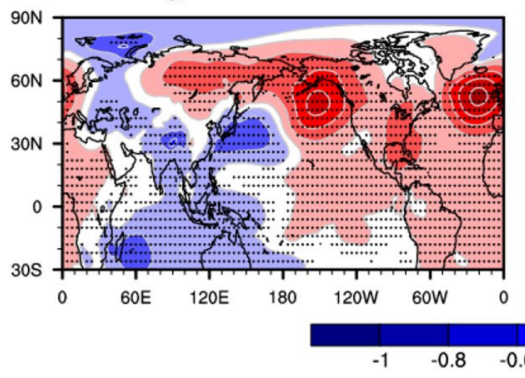

(b) GEOS 5 60-97

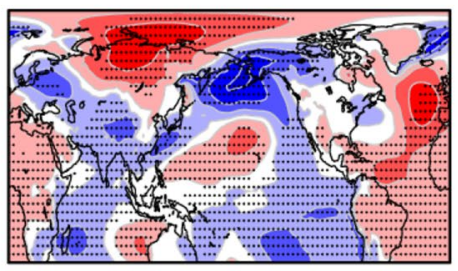

(e) ESRL CAM5.1 60-97

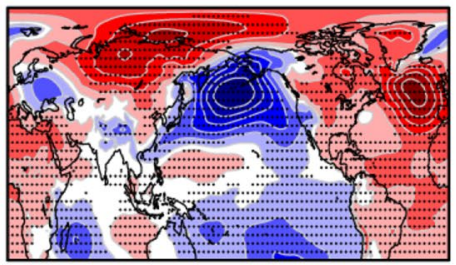

(h) LBNL CAM5.1 60-97

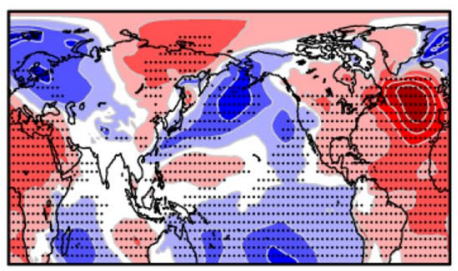

(k) GFDL AM3 60-97

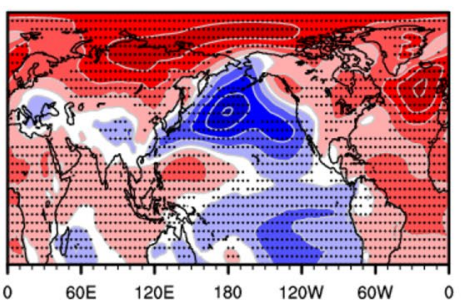

(c) GEOS 5 98-14

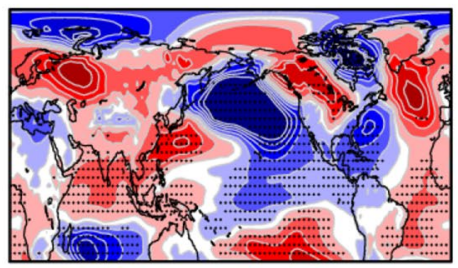

(f) ESRL CAM5.1 98-14

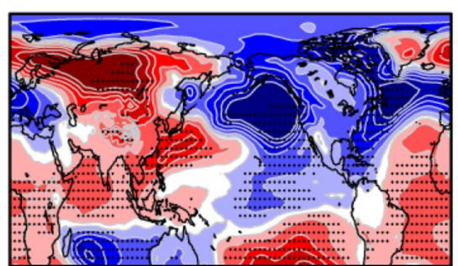

(i) LBNL CAM5.1 98-14

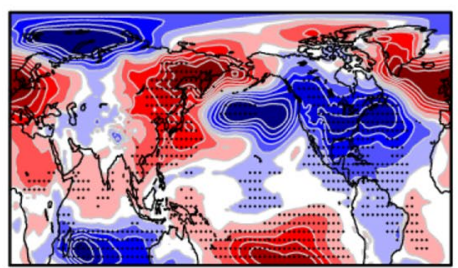

(I) GFDL AM3 98-14

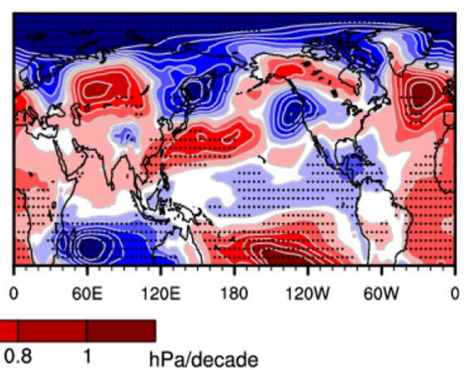

Fig. 14 Same as Fig 12 but for winter (DJF) simulated ensemble means of linear sea level pressure trends (hPa/decade) 
(a) GEOS 5 60-14

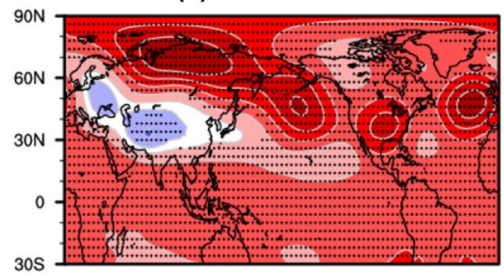

(d) ESRL CAM5.1 60-14

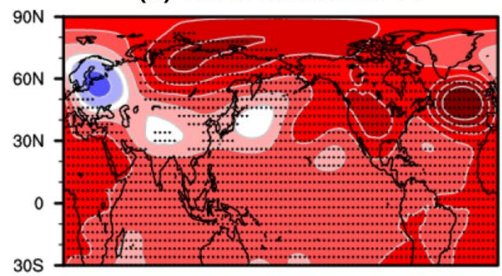

(g) LBNL CAM5.1 60-14

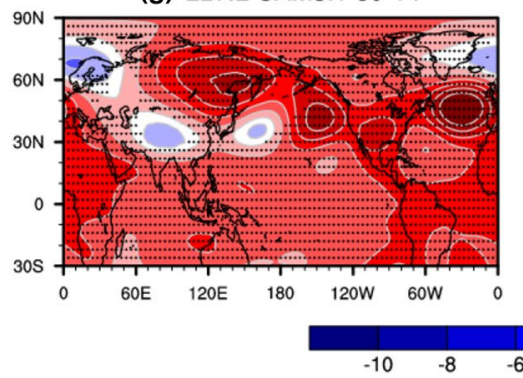

(b) GEOS 5 60-97

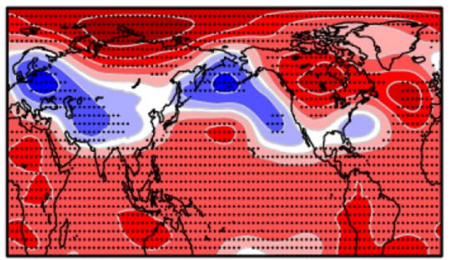

(e) ESRL CAM5.1 60-97

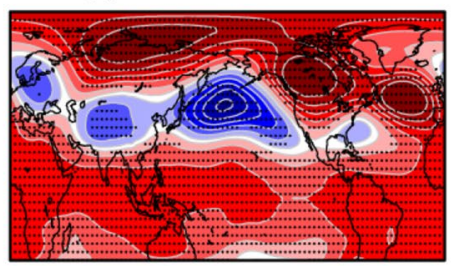

(h) LBNL CAM5.1 60-97

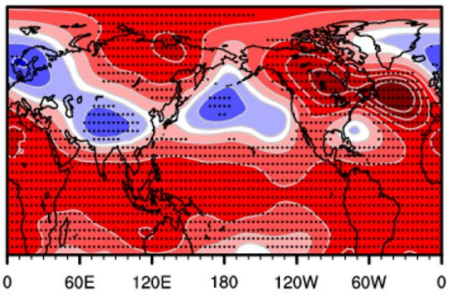

(c) GEOS 5 98-14

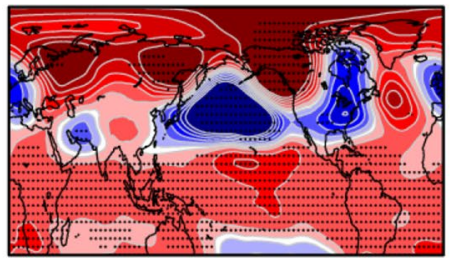

(f) ESRL CAM5.1 98-14

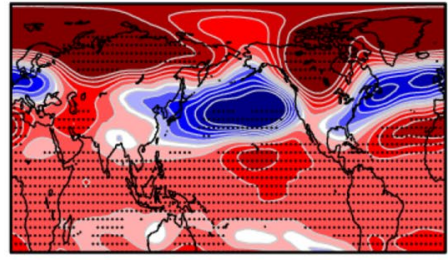

(i) LBNL CAM5.1 98-14

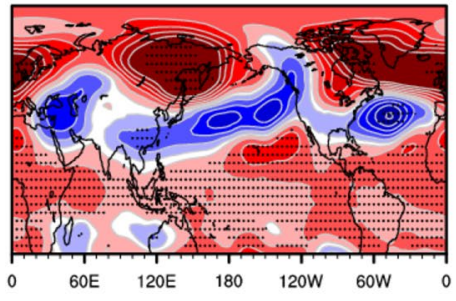

Fig. 15 Same as Fig 12 but for winter (DJF) simulated ensemble means of linear $500 \mathrm{hPa}$ geopotential height trends (Z500, m/decade). Note that Z500 in GFDL AM3 is not available for analysis

(a) AMIP UV500 Trend 60-97

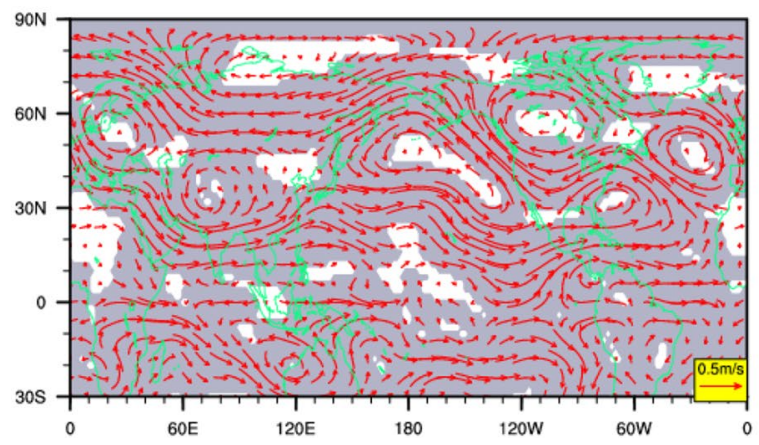

Fig. 16 Same as Fig. 12 but for winter (DJF) simulated ensemble means of linear $500 \mathrm{hPa}$ wind trends (Z500, m/sec/decade) for 28 ensemble members of ESRL CAM5.1 and LBNL CAM5.1 models. (b) AMIP UV500 Trend 98-14

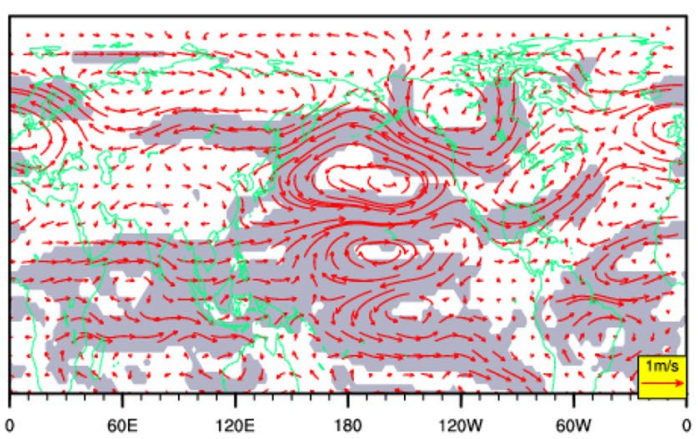

Note that $500 \mathrm{hPa}$ wind fields in GEOS 5 and GFDL AM3 are not available for analysis. Gray shaded areas have significant trends of 500-hPa zonal and/or meridional wind speed at the 5\% level 


\section{(a) TIO Precipitation indices}

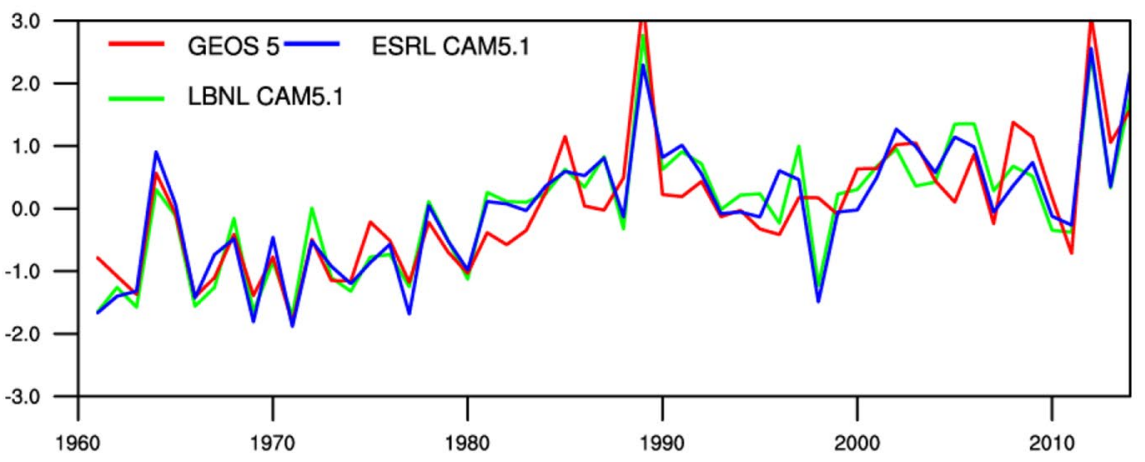

(b) GEOS 5 Precipitation (1960-2014)

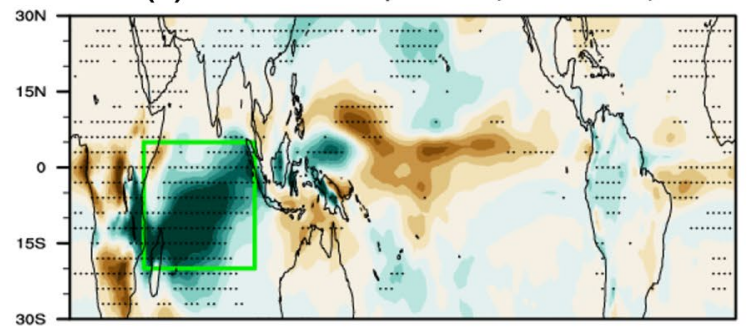

(d) ESRL CAM5.1 Precipitation (1960-2014)

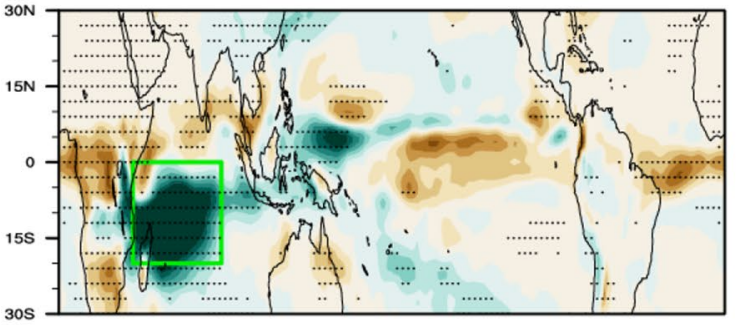

(f) LBNL CAM5.1 Precipitation (1960-2014)

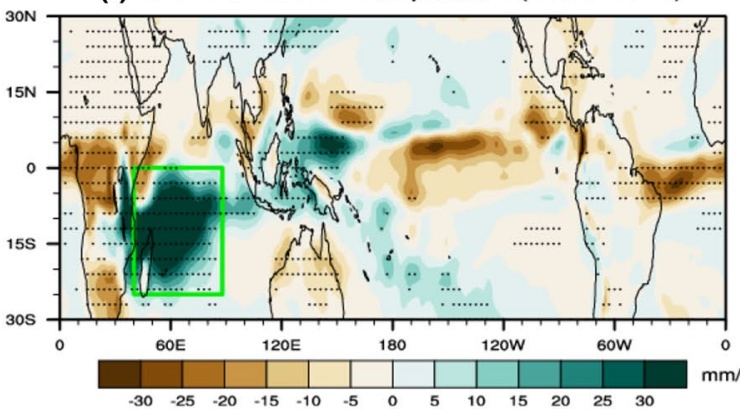

Fig. 17 a Winter (DJF) simulated precipitation indices calculated over boxes in the TIO during $1960-2014$ (in b: $40^{\circ} \mathrm{E}-100^{\circ} \mathrm{E}$, $5^{\circ} \mathrm{N}-20^{\circ} \mathrm{S}$, in $\mathrm{d}: 40^{\circ} \mathrm{E}-90^{\circ} \mathrm{E}, 0^{\circ}-20^{\circ} \mathrm{S}$, in f: $\left.40^{\circ} \mathrm{E}-90^{\circ} \mathrm{E}, 0^{\circ}-25^{\circ} \mathrm{S}\right)$. b-g Regressions of simulated (b, d, f) precipitation and (c, e, g) Z500

\section{References}

Chan D, Wu Q (2015) Attributing observed SST trends and subcontinental land warming to anthropogenic forcing during 1979-2005. J Clim 28:3152-3170

Choi KS, Oh SB, Byun HR, Kripalani R, Kim DW (2011) Possible linkage between East Asian summer drought and North Pacific Oscillation. Theor Appl Climatol 103:81-93 (c) GEOS 5 Z500 (1960-2014)

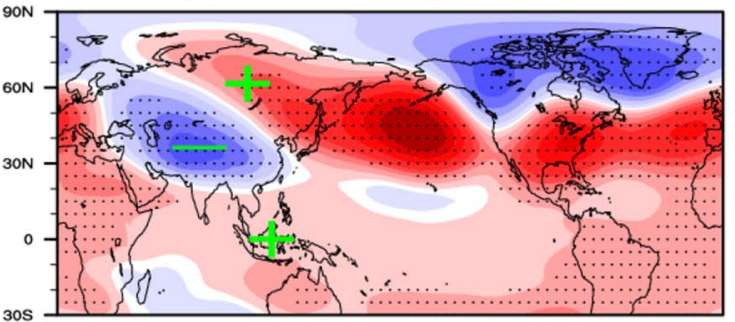

(e) ESRL CAM5.1 Z500 (1960-2014)

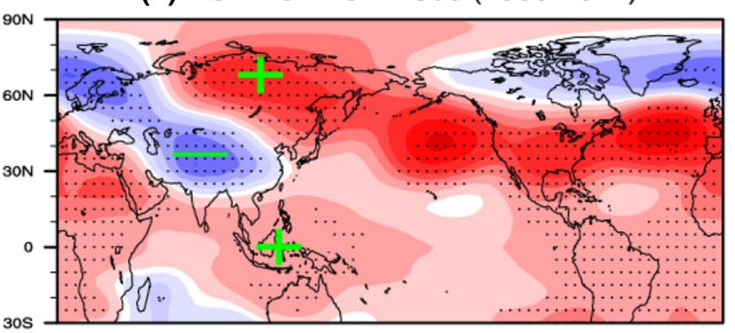

(g) LBNL CAM5.1 Z500 (1960-2014)

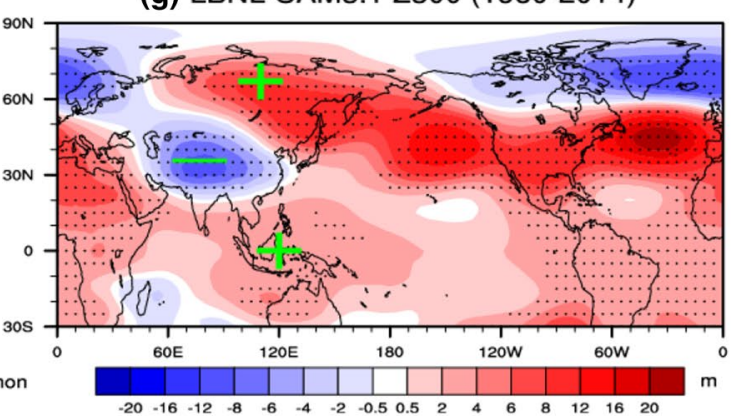

onto the corresponding TIO precipitation index in (a) for $(\mathbf{b}, \mathbf{c})$ the GEOS 5 model, (d, e) ESRL CAM5.1 and (f, g) LBNL CAM5.1. Dots mark individual grid boxes with precipitation or Z500 regression coefficients significant at the $5 \%$ level

Compo GP, Sardeshmukh PD (2009) Oceanic influences on recent continental warming. Clim Dyn 32:333-342

Deser C, Phillips AS (2009) Atmospheric circulation trends, 19502000: The relative roles of sea surface temperature forcing and direct atmospheric radiative forcing. J Clim 22:396-413

Deser C, Timlin MS, Hurrell JW (2004) Pacific interdecadal climate variability: linkages between the tropics and the North Pacific during boreal winter since 1900. J Clim 17:3109-3124 
Di Lorenzo E et al (2008) North Pacific Gyre Oscillation links ocean climate and ecosystem change. Geophys Res Lett 35:L08607

Ding Y, Liu Y, Liang S (2014) Interdecadal variability of the East Asian Winter Monsoon and its possible link with global climate change. J Meteor Res 28:693-713

Dommenget D (2009) The ocean's role in continental climate variability and change. J Clim 22:4939-4952

Donner L et al (2011) The dynamical core, physical parameterizations, and basic simulation characteristics of the atmospheric component AM3 of the GFDL global coupled model CM3. J Clim 24:3484-3519

Gao Y et al (2015) Arctic sea ice and Eurasian climate: a review. Adv Atmos Sci 32:92-114

Gates WL et al (1999) An overview of the results of the atmospheric model intercomparison project (AMIP I). Bull Am Meteorol Soc 80:335-345

Gong DY, Wang SW, Zhu JH (2001) East Asian winter monsoon and Arctic oscillation. Geophys Res Lett 28:2073-2076

Hoerling MP, Hurrell JW, Xu T, Bates GT, Phillips AS (2004) Twentieth century North Atlantic climate change. Part II: Understanding the effect of Indian Ocean warming. Clim Dyn 23:391-405

Hoskins BJ, Karoly DJ (1981) The steady linear response of a spherical atmosphere to thermal and orographic forcing. J Atmos Sci 38:1179-1196

Hu ZZ, Yang S, Wu R (2003). Long-term climate variations in China and global warming signals. J Geophys Res 108 (D19):4614

Hurrell JW, Hoerling MP, Phillips AS, Xu T (2004) Twentieth century North Atlantic climate change. Part I: assessing determinism. Clim Dyn 23:371-389

Hurrell JW, Hack JJ, Shea D, Caron JM, Rosinski J (2008) A new sea surface temperature and sea ice boundary dataset for the community atmosphere model. J Clim 21:5145-5153

Jeong JH, Ou T, Linderholm HW, Kim BK, Kim SJ, Kug JS, Chen D (2011) Recent recovery of the Siberian high intensity. J Geophys Res 116:D23102

Kalnay E et al (1996) The NCEP/NCAR 40-year reanalysis project. Bull Am Meteor Soc 77:437-471

Kim B et al (2014) Weakening of the stratospheric polar vortex by Arctic sea-ice loss. Nat Commun 5:4646. https://doi. org/10.1038/ncomms5646

Kirtman B et al (2013) Near-term climate change: projections and predictability. In: Stocker TF, Qin D, Plattner GK, Tignor M, Allen SK, Boschung J, Nauels A, Xia Y, Bex Vand, Midgley PM (eds) Climate change 2013: the physical science basis. contribution of working group I to the fifth assessment report of the intergovernmental panel on climate change Cambridge University Press, Cambridge

Knutson TR, Zeng F, Wittenberg AT (2013) Multimodel assessment of regional surface temperature trends. J Clim 26:8709-8743

Li C, Xian P (2003) Atmospheric anomalies related to interdecadal variability of SST in the North Pacific. Adv Atmos Sci 20:859-874

Li X, Li J, Li Y (2015) Recent winter precipitation increase in the middle-lower Yangtze River Valley since the late 1970s: a response to warming in the Tropical Indian Ocean. J Clim 28:3857-3879

Liang S et al (2014) Analysis of the interdecadal changes of the wintertime surface air temperature over mainland China and regional atmospheric circulation characteristics during 1960-2013. Chin. J. Atmos. Sci. (in Chinese) 38:974-992

Liu J, Curry JA, Wang H, Song M, Horton R (2012) Impact of declining Arctic sea ice on winter snow. Proc Natl Acad Sci USA 109:4074-4079.

Lu J, Greatbatch RJ, Peterson KA (2004) On the trend in northern hemisphere winter atmospheric circulation during the last half of the 20th Century. J Clim 17:3745-3760
Meehl GA, Arblaster JM., Fasullo JT, Hu A, Trenberth KE (2011) Model-based evidence of deep-ocean heat uptake during surfacetemperature hiatus periods. Nat Clim Change 1:360-364

Molod A, Takacs L, Suarez M, Bacmeister J, Song I, Eichmann A (2012) The GEOS-5 atmospheric general circulation model: mean climate and development from MERRA to Fortuna. NASA technical report series on global modeling and data assimilation, vol 28, NASA TM-2012-104606

Mori M et al (2014) Robust Arctic sea-ice influence on the frequent Eurasian cold winters in past decades. Nat Geosci. https://doi. org/10.1038/NGEO2277.

Neale R, Richter J, Park S, Lauritzen PH, Vavrus SJ, Rasch PJ, Zhang M (2013) The mean climate of the community atmosphere model (CAM4) in forced SST and fully coupled experiments. J Clim 26:5150-5168

Pegion PJ, Kumar A (2010) Multimodel estimates of atmospheric response to modes of SST variability and implications for droughts. J Clim 23:4327-4341

Schneider EK, Bengtsson L, Hu ZZ (2003) Forcing of northern hemisphere climate trends. J Atmos Sci 60:1504-1521

Schubert SD, Suarez MJ, Pegion PJ, Koster RD, Bacmeister JT (2004) Causes of long-term drought in the United States Great Plains. J Clim 17:485-503

Shin SI, Sardeshmukh PD (2011) Critical influence of the pattern of tropical ocean warming on remote climate trends. Clim Dyn 36:1577-1591. https://doi.org/10.1007/s00382-009-0732-3

Sun JQ, Ao J (2013) Changes in precipitation and extreme precipitation in a warming environment in China. Chin Sci Bull. https://doi. org/10.1007/s11434-012-5542-Z

Taylor KE, Stouffer RJ, Meehl GA (2012) An overview of CMIP5 and the experiment design. Bull Am Meteorol Soc 93:485-498

Thompson DWJ, Wallace JM, Hegerl GC (2000): Annular modes in the extratropical circulation. Part II: trends. J Clim 13:1018-1036

Trenberth KE, Branstator GW, Karoly D, Kumar A, Lau NC, Ropelewski C (1998) Progress during TOGA in understanding and modeling global teleconnections associated with tropical sea surface temperatures. J Geophys Res 103:14291-14324

Vaughan DG et al (2013) Observations: cryosphere. In: Stocker TF, Qin D, Plattner GK, Tignor M, Allen SK, Boschung J, Nauels A, Xia Y, Bex V, Midgley PM (eds) Climate change 2013: the physical science basis. Contribution of working group I to the fifth assessment report of the intergovernmental panel on climate change. Cambridge University Press, Cambridge

Von Storch H, Zwiers FW (1999) Statistical analysis in climate research. Cambridge University Press, Cambridge

Wang L, Chen W (2014) The East Asian winter monsoon: re-amplification in the mid 2000s. Chin Sci Bull 59:430-436

Wang B, Wu RG, Fu XH (2000) Pacific-East Asian teleconnection. Part I: how does ENSO affect East Asian climate? J Clim 13:1517-1536

Wang L, Chen W, Huang R (2007) Changes in the variability of North Pacific oscillation around 1975/1976 and its relationship with East Asian winter climate. J Geophys Res 112:D11110

Wang L, Chen W, Huang R (2008) Interdecadal modulation of PDO on the impact of ENSO on the East Asian winter monsoon. Geophys Res Lett 35:L20702

Wang B, Wu Z, Chang CP, Liu J, Li J, Zhou T (2010) Another look at interannual-to-interdecadal variations of the East Asian winter monsoon: the northern and southern temperature modes. J Clim 23:1495-1512

Wu Q (2010) Associations of diurnal temperature range change with the leading climate variability modes during the northern hemisphere wintertime and their implication on the detection of regional climate trends. J Geophys Res 115:D19101 
Wu Q, Karoly DJ (2007) Implications of changes in the atmospheric circulation on the detection of regional surface air temperature trends. Geophys Res Lett 34:L08703

Wu Q, Straus DM (2004), AO, COWL, and observed climate trends. J Clim 17:2139-2156

Wu Q, Zhang X (2010) Observed forcing-feedback processes between northern hemisphere atmospheric circulation and Arctic sea ice coverage. J Geophys Res 115:D14119

Wu B, Su J, Zhang R (2011) The effects of autumn-winter arctic sea ice on winter Siberian high. Chin Sci Bull 56:3220-3228

Wu B, Su J, D'Arrigo R (2015) Patterns of Asian winter climate variability and links to Arctic sea ice. J Clim 28:6841-6858

Xie P, Arkin PA (1997) Global precipitation: A 17-year monthly analysis based on gauge observations, satellite estimates, and numerical model outputs. Bull. Amer. Meteor. Soc., 78:2539-2558.

Yang J, Liu, Q, Xie SP, Liu Z, Wu L (2007) Impact of the Indian Ocean SST basin mode on the Asian summer monsoon. Geophys Res Lett 34:L02708.

Yang J, Liu Q, Liu Z (2010) Linking observations of the Asian monsoon to the Indian Ocean SST: possible roles of Indian Ocean basin mode and dipole mode. J Clim 23:5889-5902.
Ye X, Zhang W, Luo M (2017) The North Pacific Gyre Oscillation and East Asian summer precipitation. Atmos Sci Lett 17:531-537

Zhai P, Zhang X, Wan H, Pan X (2005) Trends in total precipitation and frequency of daily precipitation extremes over China. J Clim 18:1096-1108.

Zhang R, Sumi A, Kimoto M (1996) Impact of El Nino on the East Asia monsoon: a diagnostic study of the ' $86 / 87$ and ' $91 / 92$ events. J Meteor Soc Jpn 74:49-62.

Zhang Z, Gong D, Hu M, Guo D, He X, Lei Y (2009) Anomalous winter temperature and precipitation events in southern China. $\mathrm{J}$ Geogr Sci 19:471-488.

Zheng J, Liu Q, Wang C, Zheng X (2013) Impact of heating anomalies associated with rainfall variations over the Indo-Western Pacific on Asian atmospheric circulation in winter. Clim Dyn 40:2023-2033

Zuo J, Ren HL, Wu B, Li W (2016) Predictability of winter temperature in China from previous autumn Arctic sea ice. Clim Dyn 47:2331-2343 